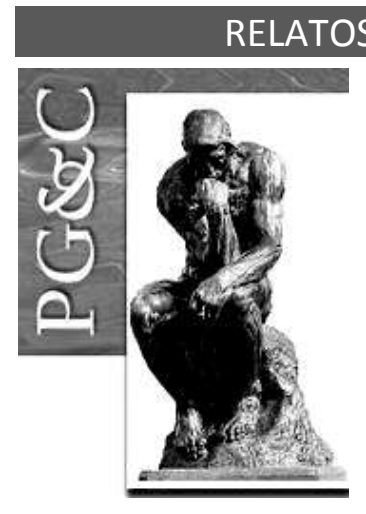

\title{
GESTÃO DO CONHECIMENTO, INOVATIVIDADE, CRIATIVIDADE E DESEMPENHO INOVADOR EM EMPRESAS DE SAÚDE
}

\author{
Cicero Aparecido Bezerra \\ Doutor em Engenharia de Produção pela Universidade Federal de Santa \\ Catarina, Brasil. Professor da Universidade Federal do Paraná, Brasil. \\ E-mail: cicero.bezerra@ufpr.br \\ Débora Cristine Marques \\ Graduada em Gestão da Informação pela Universidade Federal do Paraná, \\ Brasil. Gestora financeira da Medical Import Ltda., Brasil. \\ E-mail: debora.cristinem@gmail.com
}

\begin{abstract}
Resumo
A pesquisa tem como objetivo verificar a existência de relação entre gestão do conhecimento, criatividade organizacional e a predisposição à inovação, com o faturamento e o próprio desempenho inovador de empreendimentos do segmento de saúde. É uma pesquisa exploratória, de viés quantitativo, com o uso de survey realizada em uma amostra não-probabilística por conveniência geográfica composta por 62 empresas privadas da área de saúde localizadas no município de Curitiba no Paraná, que empregou análises quantitativas bi e multivariada. Os resultados apontam para expressivas associações entre os elementos pesquisados, além de indicar também a relação do tempo de existência dos empreendimentos analisados com a criatividade organizacional e, produtos/serviços e processos inovadores.
\end{abstract}

Palavras-chave: Gestão do conhecimento. Inovatividade. Criatividade. Empresas de saúde.

\section{KNOWLEDGE MANAGEMENT, INNOVATIVITY, CREATIVITY AND INNOVATIVE PERFORMANCE IN HEALTH COMPANIES}

\begin{abstract}
The research aims to verify the existence of a relationship between knowledge management, organizational creativity and the predisposition to innovation, with the billing and the own innovative performance of enterprises in the health segment. It is an exploratory, quantitative research using a survey applied in a non-probabilistic sample by geographic convenience composed of 62 private health companies located in the city of Curitiba, Paraná, which used bi and multivariate quantitative analyzes. The results indicate to expressive associations among the researched elements, besides indicating the relation of the time of existence of the enterprises analyzed with the organizational creativity and products/services and innovative processes.
\end{abstract}

Keywords: Knowledge management. Innovativity. Creativity. Health companies.

\section{INTRODUÇÃO}

As empresas de saúde apresentam um destacado papel no cenário socioeconômico brasileiro. Segundo Andrade et al., (2018) no nível macroeconômico, esta atividade gera maiores níveis de riqueza, investimentos em capital humano e, consequentemente, maior

Perspectivas em Gestão \& Conhecimento, João Pessoa, v. 9, n. 2, p. 56-84, maio/ago. 2019. DOI: http://dx.doi.org/10.21714/2236-417X2019v9n2p56

http://periodicos.ufpb.br/ojs2/index.php/pgc. ISSN: 2236-417X. Publicação sob Licença (cc) EY-Nc-ND 
desenvolvimento. Para Reis et al., (2018) trata-se de um segmento de especial relevância para o desenvolvimento socioeconômico uma vez que ao congregar empresas de produção de bens e serviços, muitas vezes de alta tecnologia, atua na atenção à saúde humana. Da mesma forma, Colauto e Beuren (2003) observam que são organizações que possuem responsabilidade social, tanto em relação à qualidade de vida, quanto a atender os valores básicos da sociedade em que está inserida.

Contudo, são empresas que atuam em um mercado bastante competitivo: Pitassi, et al., (2014) registram a intensidade da competição vivenciadas por estas organizações; enquanto Bahia (2018), denomina como "feroz" o nível de competição existente entre as empresas do segmento de saúde; por sua vez, Paim et al., (2011) afirmam que o Brasil possui um complexo conjunto de organizações públicas e privadas voltadas à saúde cujos prestadores e compradores de serviços competem entre si.

Neste sentido, a literatura especializada tem sido abundante ao associar a competitividade à inovação (SOETE, 2019; JONES; BARNIR, 2019), gestão do conhecimento (ANTONELLI, 2018; JOHANSON; LOOF, 2016) e, criatividade (FETRATI; NIELSEN, 2018; GOLLER; BESSANT, 2017). Porém, as pesquisas acadêmicas sobre organizações da área de saúde não parecem considerar estes temas de maneira tão frequente. Em uma busca na biblioteca eletrônica Scielo", realizada em 15 de abril de 2019, pelos termos ("organizações" OU "empresas") E "saúde" E ("inovação" OU "criatividade" OU "conhecimento") no campo "Título" trouxe apenas um artigo abordando um estudo de caso em uma unidade vascular de um hospital de alta complexidade, que identificava "elementos críticos de gestão" capazes de transformar esta unidade em uma organização de aprendizagem (GONÇALO; BORGES, 2010). Já no portal de periódicos CAPES², na mesma data, uma busca avançada no campo "Título", em artigos de periódicos revisados por pares, com as palavras "organizações" E "saúde" retornou 113 registros, e com as palavras "empresas" E "saúde" retornou 63 artigos. Deste conjunto, 18 deles apresentaram os termos "inovação", "conhecimento" ou "criatividade" em seus resumos, sendo que deste total apenas quatro deles abordaram estes termos no contexto organizacional, porém isoladamente (MELO; TANAKA, 2001; VASCONCELOS, 2014; AZEVEDO; BRAGA NETO; SA, 2002; MALIK, 1992).

O presente estudo pretende, justamente, ocupar um espaço na carência de pesquisas que buscam associar a inovação, gestão do conhecimento e criatividade, às organizações da área de saúde, a partir do seguinte problema de pesquisa: as relações existentes entre gestão do conhecimento, criatividade organizacional e inovatividade encontram-se associadas ao desempenho inovador e no faturamento das empresas do segmento de saúde no município de Curitiba no Paraná (PR)? Assim sendo, o objetivo da pesquisa é verificar a existência de relação entre gestão do conhecimento, criatividade organizacional e a predisposição à inovação, com o faturamento e o próprio desempenho inovador de empreendimentos do segmento de saúde.

\section{REFERENCIAL TEÓRICO}

A presente seção as traz definições básicas sobre os temas nas quais o estudo se subsidia. É importante esclarecer que não se pretende esgotar os elementos conceituais, mas sim apresenta-los no contexto do presente estudo.

\footnotetext{
${ }^{1}$ www.scielo.br

${ }^{2}$ www.periodicos.capes.gov.br
} 


\subsection{Gestão do conhecimento}

Nas organizações, o termo 'conhecimento' é comumente entendido como um recurso competitivo (PEREIRA; SILVA, 2018; MACHADO, 2018; GEHL, 2015) e, em sendo desta forma, há que se gerenciá-lo (MCIVER; FITZSIMMONS; FLANAGAN, 2016). Conceitualmente, a gestão do conhecimento tem sido entendida como a capacidade da organização em dominar, desenvolver e direcionar a expertise da organização aos objetivos estratégicos (NANDITA, 2013; LOON, 2019). Já Burger, et al., (2018) e Donnelly (2019) associam a gestão do conhecimento à própria expectativa de eficácia e sucesso da empresa.

Neste sentido, não são raros os modelos teóricos que propõem representações do processo de gestão do conhecimento, tais como: (1) a construção e uso do conhecimento, de Wiig (1995) que segue o princípio de que o conhecimento deve ser organizado a partir de seu uso (PEREIRA; SILVA, 2018), disposto de tal modo em uma rede semântica (BURGER, et al., 2018), na qual são consideradas características como integridade, conectividade, congruência e, perspectiva e objetivos (CORREA; ZIVIANI; MARTINS, 2018); (2) o espaço da informação, de Boisot (1999), representa o conhecimento como um ativo organizacional (NEVES, et al., 2018), sendo obtido a partir da adequada estruturação de dados, codificação e difusão da informação (EVANS; FRISSEN; WENSLEY, 2018); (3) epistemologia organizacional, de von Krogh e Roos (1995), que identifica como e porquê os indivíduos, dentro de uma organização (e mesmo a própria organização), desenvolvem o conhecimento (MACEDO, et al., 2017) a partir de fatores impeditivos (BURGER, et al., 2018) e facilitadores (GONZALEZ; MARTINS, 2015); (4) a espiral do conhecimento, de Nonaka e Takeuchi (1995) que compreende a conversão do conhecimento tácito para o explícito, a partir de processos sucessivos de socialização, externalização, combinação e internalização entre os indivíduos (SCATOLIN, 2015); (5) a construção de sentido, de Choo (2006), apresentado em 1998, que enfatiza a criação de significado a partir comportamentos adaptativos direcionados ao alcance de objetivos (BLOODGOOD, 2019), embasados em informação (SANTOS; SANTOS; DAMIAN, 2018) e conhecimentos externos (DENFORD; FERRISS, 2018).

Um modelo que leva em consideração aspectos substanciais do que os estudos em gestão do conhecimento têm apresentado é proposto por Gold, Malhotra e Segars (2001), no qual estende elementos teóricos de gestão do conhecimento a uma dimensão programática, denominada 'efetividade organizacional' que é dada em função de duas capacidades organizacionais: 'infraestrutura do conhecimento' e 'processos do conhecimento'. A primeira é composta por elementos tecnológicos (LOON, 2019; WALSH; O'BRIEN, 2018; NEVES, et al., 2018), como sistemas de informação, comunicação, colaboração e, inteligência de negócios; culturais (COOPER, et al., 2016; RICE; HEINZ; VAN ZOONEN, 2019), tais como interação entre pessoas, visão corporativa, sistema de valores e; estruturais (LUPTON; BEAMISH, 2014; MARQUES, et al., 2019), que envolvem a racionalização de unidades e funções. Já os 'processos do conhecimento' envolvem aquisição, conversão, aplicação e proteção do conhecimento da organização (PARK; HOWARD; GOMULYA, 2018; THALMANN; SARIGIANNI, 2016; BISCOTTI; D'AMICO; MONGE, 2018).

Ainda que a sustentação teórica da gestão do conhecimento vem apresentando consolidação ao longo do tempo (BEZERRA; GUIMARÃES, 2014), é prudente considerar as críticas a este conceito. Para Sarayeh, Mardawi e Dmour (2012), o modelo de Nonaka é não somente simplista e subjetivo, como a codificação do conhecimento não é possível em todos os casos. 0 próprio Ikujiro Nonaka, juntamente com Georg von Krogh e Kazuo Ichijo (VON KROGH; ICHIJO; NONAKA, 2000), alerta para o fato de que o conceito de gestão do conhecimento é, por si só, limitado. Para Capurro (2011), o que pode ser gerenciado é apenas a informação - que é parte do processo de criação do conhecimento. Segundo Ruiz (2010), a dificuldade que a gestão do conhecimento apresenta ao lidar com o conhecimento tácito (tanto de pessoas, quanto da

Perspectivas em Gestão \& Conhecimento, João Pessoa, v. 9, n. 2, p. 56-84, maio/ago. 2019. 
organização) a aproxima mais de elementos abstratos (tais como 'arte') do que de uma disciplina científica propriamente dita.

\subsection{Inovatividade e desempenho inovador}

A inovação tem sido recorrentemente retratada como elemento de fundamental de importância à competitividade e produtividade das empresas (STROLL; KORHONEN, 2018; OLIVA, et al., 2019) e, até mesmo, como mecanismo de desenvolvimento da própria sociedade (LOWE; FELDMAN, 2018; MCDOWELL et al., 2018). Para Schumpeter (1934) a inovação é amplamente associada ao lançamento de produtos ou serviços inéditos, novas maneiras de condução do processo de produção, desenvolvimento de fornecedores e mercados até então inexplorados ou, o estabelecimento de nova organização da empresa. Já a Organisation for Economic Co-operation and Development (2018) define inovação como sendo produto ou processo (ou ambos) novos ou melhorados que se distinguem significativamente de configurações anteriores, que tenham sido tornados disponíveis aos seus usuários.

Enquanto várias pesquisas têm focado em indicadores de inovação, avaliando elementos como entradas e saídas do processo (DURAN, et al., 2016; DIÉGUEZ-SOTO; MANZANEQUE; ROJO-RAMÍREZ, 2016; FRANCO; OLIVEIRA, 2017), uma categoria de estudos busca compreender as condições organizacionais que propiciam a inovação, entendidas como 'inovatividade' (NASIEROWSKI; ARCELUS, 2012; LINTON, 2019; JONES; BARNIR, 2019).

Neste sentido, Quandt, Ferraresi e Bezerra (2017) propõem um modelo que associa o desempenho inovador a dez dimensões de inovatividade organizacionais, a saber: (1) estratégia, responsável por explicitar o papel da inovação no contexto geral (BAUM; LOOF; NABAVI, 2019; CANDI, et al., 2018; SCHIAVI; BEHR, 2018); (2) liderança, que estabelece linhas de comando, alinhadas ao item anterior (SCHOEMAKER; HEATON; TEECE, 2018; TEECE, 2018; RAMOS; FIGUEIREDO; PEREIRA-GUIZZO, 2018); (3) cultura, mantendo um ambiente propício à experimentação (ROACH et al., 2018; GRIESAR; BESSANT; BERNSCHNEIDER-REIF, 2018; PADILHA; GOMES, 2016); (4) estrutura organizacional, que estabelece os parâmetros sistêmicos da empresa orientados à facilitação de ações que conduzem a inovação (TERSTRIEP; LUTHJE, 2018; TEECE, 2018; OLIVEIRA; TERENCE, 2018); (5) processos, capazes de formalizar a transformação dos resultados das interações em conhecimento aplicado (RANK; STRENGE, 2018; LONGONI; CAGLIANO, 2018; RIBEIRO; CHEROBIM, 2017); (6) recursos humanos, que determina a seleção e manutenção de pessoas aptas ao desenvolvimento da estratégia de inovação (AUDRETSCH; LINK, 2018; ALVES; GALINA; DOBELIN, 2018; HAHN, 2019); (7) rede de relacionamentos, cuja finalidade é promover sinergia interna e externa à empresa (FORSMAN; TEMEL, 2016; DORAN; O'LEARY, 2016; VASCONCELOS; OLIVEIRA, 2018); (8) infraestrutura tecnológica, responsável pela sustentação tecnológica das iniciativas de inovação (TIDD; BESSANT, 2018; SOETE, 2019; ROLDAN; HANSEN; GARCIA-PEREZ-DE-LEMA, 2018); (9) mensuração, necessária à aferição dos esforços e resultados inovadores (STROLL; KORHONEN, 2018; LAING, 2018; VASCONCELOS; OLIVEIRA, 2018) e; (10) aprendizagem, que mantém o conhecimento resultante como um ativo da organização (KINDER; STENVALL; MEMON, 2019; VOS, et al., 2018; CARVALHO, et al., 2017).

Embora a literatura especializada seja abundante em retratar a inovação como vantajosa às empresas e à sociedade, é possível encontrar algumas críticas relacionadas ao tema. Para Sood e Tellis (2009) há que se ter uma visão cautelosa sobre os benefícios, para as empresas, em inovar: (1) das três atividades de inovação (inicialização, desenvolvimento e comercialização), a comercialização é a que apresenta as menores taxas de retorno; (2) retornos sobre o lançamento de novos produtos são os mais baixos, entre eventos como alianças, funding, expansão, protótipos e, patentes; (3) os retornos são consistentemente maiores em empresas de menor porte que focam em um número reduzido de tecnologias. Já

Perspectivas em Gestão \& Conhecimento, João Pessoa, v. 9, n. 2, p. 56-84, maio/ago. 2019. 
Amorim e Frederico (2008) observam que a inovação pode causar concentração de mercado, excluindo as pessoas que não possuem condições de acesso ao bem, visto que produtos/serviços inovadores, ao menos em um primeiro momento, são lançados com preços "extorsivos". Em relação à inovação organizacional, Hernandez e Caldas (2001) notam a ineficiência de alguns modelos em representar a superação de barreiras contra as mudanças internas.

\subsection{Criatividade organizacional}

Enquanto o conhecimento pode ser tomado como um ativo necessário à inovação (RIBIÈRE; WALTER, 2013; PRADO; FISCHER, 2013), por sua vez, também a criatividade tem sido recorrentemente associada, tanto à criação do conhecimento (CERNE et al., 2014; GILSON et al., 2013; GONG et al., 2013), quanto à própria inovação (CLAUß, 2012; DENTI; HEMLIN, 2012; DAVIS; EISENHARDT, 2011). Ao nível do indivíduo, a criatividade é definida como sendo a habilidade em expor comportamento distinto ao apresentar soluções alternativas para os problemas (GUILFORD, 1950). Posteriormente Amabile (1998), levando esta definição ao ambiente corporativo, distinguiu o termo indo além da geração de ideias - caso estas não possuam características como utilidade, objetividade, e executáveis, não podem ser consideradas criativas.

A criatividade, nas organizações, encontra-se associada a elementos gerenciáveis (MUZZIO; PAIVA JÚNIOR, 2018; GOLLER; BESSANT, 2017; CIRELLA, 2016), ainda que exija um delicado equilíbrio entre eles (AMABILE, 2000; BEZERRA; GUIMARÃES, 2017) - o que faz com que existam posições que questionam a extensão na qual a criatividade, enquanto recurso organizacional possa ser, de fato, gerenciada (FORTWENGEL; SCHUßLER; SYDOW, 2017). Este dilema leva à necessidade do estabelecimento de modelos para a representação da criatividade integrada à inovação e à gestão do conhecimento, em um contexto organizacional (MUZZIO; PAIVA JÚNIOR, 2018).

Neste sentido, um dos modelos mais empregados para a representação da criatividade organizacional é o modelo KEYS (CULPEPPER, 2010; GOMES; RODRIGUES; VELOSO, 2016), desenvolvido por Amabile, et al., (1996), no qual o resultado criativo desempenhado por um funcionário é formado por elementos como: (1) encorajamento organizacional (GRABNER, 2014; NONAKA; HIROSE; TAKEDA, 2016), que pressupõe a existência de condições, mantidas pela organização, capazes de fornecer a devida segurança ao trabalhador, na apresentação de ideias criativas; incentivo do supervisor direto (MUZZIO, 2017; BOLDEN; O'REGAN, 2018; EISELE, 2017), na qual o trabalhador possa se sentir estimulado pelo supervisor na criação de novas ideias e; da equipe de trabalho (RODRÍGUEZ-SÁNCHEZ et al., 2017; DAVILA; DITILLO, 2017), onde existe apoio, entre seus pares, no desenvolvimento de soluções criativas; (2) liberdade de ação (VINCENT; KOUCHAKI, 2015; MOULANG, 2015), na qual o indivíduo sente a devida autonomia para a promoção da sua criatividade, adequadamente voltada para soluções organizacionais; (3) disponibilidade de recursos (FETRATI; NIELSEN, 2018; FORTWENGEL; SCHUßLER; SYDOW, 2017), onde a efetiva alocação de recursos necessários às atividades de criação é prática recorrente na organização; (4) trabalho desafiador (STERNBERG, 2018; HIRST, et al., 2018; CHARNESS; GRIECCO, 2019), em que as atividades laborais mostram-se incitantes a ponto de requererem soluções criativas; (5) carga de trabalho (SMITH, 2017), a qual não pode exceder a capacidade natural do indivíduo em executá-la, comprometendo sua aptidão e, até mesmo, a qualidade dos resultados e; (6) impedimentos organizacionais (KREMER; VILLAMOR; AGUINIS, 2019; ALBERS et al., 2018), relacionados às rígidas e conservadoras estruturas da organização, bem como conflitos que, naturalmente, são fatores impeditivos ao desenvolvimento da criatividade nos trabalhadores.

Perspectivas em Gestão \& Conhecimento, João Pessoa, v. 9, n. 2, p. 56-84, maio/ago. 2019. 
A criatividade organizacional, como tema de estudos, não tem passado isenta de críticas. Segundo Glaveanu e Lubart (2014) estruturas conceituais que tentam sumarizar a criatividade se, por um lado, permitem a realização de comparações, por outro, não identificam os tipos de relações sociais mais importantes para se atingir a criatividade. Para Wilson (2009) a criatividade, como campo de estudo, apresenta limitações ao ser abordada de maneira probabilística, visto que uma solução criativa, por exemplo, não pode ser determinada, por não ser empírica até o momento de sua própria existência. Já em termos práticos Carlson e Wilmot (2006) trazem à tona a dicotomia percebida na qual empresas que focam em criatividade não conseguem serem disciplinadas.

\section{PROCEDIMENTOS METODOLÓGICOS}

A presente pesquisa emprega análises estatísticas multi e bivariadas no sentido de tornar explícita a associação existente entre condições habilitadoras da inovação, gestão do conhecimento e, criatividade organizacional, e a relação destas quanto às características das organizações do segmento de saúde, localizadas em Curitiba - PR. A amostra consistiu de 62 clínicas, consultórios isolados, hospitais e unidades de apoio e mistas (de um total de 2.815 entidades empresariais de saúde) presentes no Cadastro Nacional de Estabelecimentos de Saúde (2019) localizadas no município. Trata-se, portanto, de uma amostra não-probabilística por conveniência geográfica - o que, naturalmente, restringe os achados tão somente à própria amostra.

Como instrumento de coleta de dados optou-se por empregar o questionário utilizado por Bezerra e Guimarães (2017). O Quadro 1 apresenta as questões que tratam das condições organizacionais habilitadoras da inovação (IN) e desempenho inovador, dividido em produtos/serviços inovadores (SI) e processos inovadores (PI):

Quadro 1 - Questões sobre inovatividade e desempenho inovador

Quanto à estratégia, na organização em que atuo...

... os componentes estratégicos (declaração de missão, visão, valores, objetivos) priorizam a inovação.

... o desempenho estratégico é monitorado e avaliado, bem como o processo de inovação.

Quanto à liderança, na organização em que atuo...

... os líderes promovem o compartilhamento e aprendizagem, demonstrando isso pelo próprio

exemplo.

... os líderes buscam constantemente soluções novas e pouco usuais, estimulando novas ideias.

Quanto à cultura, na organização em que atuo...

... ocorre formação equipes multidisciplinares com autonomia para desenvolver projetos inovadores.

... há elevado sentimento de confiança entre empresa e funcionários.

Quanto à estrutura, na organização em que atuo...

... a estrutura facilita que pessoas de áreas distintas desenvolvam inovações.

... a estrutura organizacional facilita a mobilidade entre cargos e ampla comunicação entre departamentos.

Quanto aos processos, na organização em que atuo...

... é adotado um processo formal de gerenciamento de projetos para implantar inovações.

... existem métodos claros para planejamento de todo o ciclo de desenvolvimento de novos produtos.

Quanto às pessoas, na organização em que atuo...

... o processo de recrutamento e seleção valoriza o comportamento inovador e empreendedor.

... existem estratégias explícitas para a retenção de talentos para a inovação na empresa.

Quanto ao networking, na organização em que atuo...

... há vínculos parcerias com universidades e institutos de pesquisa com seus objetivos estratégicos.

... os funcionários sabem da importância das redes externas como forma de sustentação da

competitividade.

Perspectivas em Gestão \& Conhecimento, João Pessoa, v. 9, n. 2, p. 56-84, maio/ago. 2019. 
Quanto às TICs, na organização em que atuo...

... as informações mais relevantes estão documentadas e organizadas em espaços virtuais de acesso geral.

... as pessoas usam efetivamente os recursos de acesso e compartilhamento dos sistemas de informações.

Quanto à mensuração, na organização em que atuo...

... existem mecanismos formais para se comparar com a concorrência.

... os resultados são medidos sob várias perspectivas e usa as medidas como forma de aprendizado.

Quanto à aprendizagem, na organização em que atuo...

... a avaliação do desempenho é uma atividade de aprendizagem, e não punitiva ou controladora.

... o aprendizado é uma responsabilidade integral e diária de todos.

Sobre os resultados inovadores, quanto aos produtos/serviços desenvolvidos, na organização em que atuo...

... são frequentemente percebidos, pelos clientes, como muito inovadores.

... temos lançados produtos/serviços mais criativos em relação aos concorrentes.

... temos lançados produtos/serviços mais rapidamente em relação aos concorrentes.

... a participação de novos produtos/serviços na receita total tem sido maior em relação aos concorrentes.

Sobre os resultados inovadores, quanto aos processos internos, na organização em que atuo...

... implementamos um alto percentual de melhorias.

... conquistamos melhorias significativas no processo de produção.

... conquistamos melhorias significativas nos processos organizacionais.

Fonte: adaptado de Bezerra e Guimarães (2017)

Trata-se de elementos fartamente empregados em estudos sobre as condições organizacionais relacionadas à inovação e já utilizados anteriormente na pesquisa de Quant, Ferraresi e Bezerra (2017). Já o conjunto de questões sobre as capacidades organizacionais para a gestão do conhecimento (GC) pode ser visualizado no Quadro 2:

Quadro 2 - Questões sobre gestão do conhecimento

Quanto à cultura organizacional, na organização em que atuo..

... a visão geral está claramente comunicada.

... as pessoas são encorajadas a explorar e a experimentar.

... as pessoas são encorajadas a pedir ajuda quando necessário.

Quanto à estrutura organizacional, na organização em que atuo...

... a divisão departamental estimula a interação e o compartilhamento de conhecimento.

... existe um sistema formal de recompensa ao compartilhamento do conhecimento.

... existem estruturas nas quais o comportamento coletivo é predominante ao comportamento individual.

Quanto à tecnologia empregada na organização em que atuo...

... possibilita a colaboração entre pessoas.

... formata e categoriza o conhecimento para usos futuros.

... possibilita o acesso ao conhecimento quando necessário.

Quanto à aquisição do conhecimento, na organização em que atuo...

... esta é uma prática formal.

... existem processos para compartilhamento de conhecimento com parceiros.

... existem processos formais para identificação de melhores práticas.

Quanto à conversão do conhecimento, na organização em que atuo...

... existem processos para descartar, repor e filtrar o conhecimento.

... existem processos formais para compartilhamento entre os colaboradores.

... existem processos formais para conversão do conhecimento em novos produtos/serviços. 
Quanto à aplicação do conhecimento, na organização em que atuo...

... existem processos para aplicar o conhecimento criado a partir de experiências.

... existem fontes formais de conhecimento para abordar novos desafios.

... o conhecimento é rapidamente aplicada na solução de problemas.

Fonte: adaptado de Bezerra e Guimarães (2017)

O conjunto de questões apresentado no Quadro 2 baseou-se, principalmente, no modelo proposto por Gold, Malhotra e Segars (2001). Finalmente, para as condições ambientais para o desenvolvimento da criatividade organizacional (CO), optou-se por empregar o modelo KEYS (AMABILE et al., 1996) reduzido por Rosello e Tran (2011), conforme mostrado no Quadro 3:

Quadro 3-Questões sobre a criatividade organizacional

Quanto ao encorajamento organizacional, na organização em que atuo...

... novas ideias são regularmente encorajadas.

... as pessoas são reconhecidas pela criatividade.

... as pessoas são recompensadas pela criatividade.

Quanto ao encorajamento da supervisão, na organização em que atuo...

... os supervisores comunicam claramente os objetivos à equipe.

... os supervisores possuem boas habilidades interpessoais.

... os supervisores apoiam as equipes de trabalho.

Quanto aos grupos de trabalho, na organização em que atuo...

... as pessoas se ajudam mutuamente.

... há um sentimento de confiança mútuo.

Quanto à disponibilidade de recursos, na organização em que atuo...

... os orçamentos são adequados.

... as pessoas conseguem os materiais necessários às suas atividades com facilidade.

Quanto aos desafios, na organização em que atuo...

... as tarefas desafiam as capacidades dos colaboradores.

... as pessoas se sentem desafiadas.

Quanto à liberdade de ação, na organização em que atuo..

... as pessoas têm liberdade de decidir como conduzir seus projetos.

... as pessoas têm liberdade de escolher em qual projeto irão participar.

Quanto aos impedimentos organizacionais, na organização em que atuo...

... existem problemas políticos.

... as pessoas são resistentes às novas ideias.

... existem competições que podem ser destrutivas.

... a alta gerência não assume riscos.

Quanto à carga de trabalho, na organização em que atuo...

... existe uma forte pressão em relação aos prazos.

... as expectativas são realistas em relação aos objetivos traçados.

Fonte: adaptado de Bezerra e Guimarães (2017)

Para cada questão dos Quadros 1, 2 e 3, os respondentes (gestores das organizações de saúde) forneceram sua percepção quanto à intensidade com que as práticas organizacionais de IN, GC e CO são empregadas nas organizações, em uma escala de 0 a 10 (sendo que 0 equivale à inexistência daquela prática organizacional e, 10 equivalendo a uma prática intensamente empregada) - já para $\mathrm{SI}$ e $\mathrm{PI}$, a escala de 0 a 10 corresponde à inovação percebida, pelos respondentes, nos respectivos quesitos.

Além das questões referentes à $\mathrm{GC}, \mathrm{CO}, \mathrm{IN}, \mathrm{SI}$ e $\mathrm{PI}$, as empresas foram caracterizadas quanto ao ano de fundação, número de colaboradores (questões abertas), principal segmento de atuação (questão nominal fechada) de acordo com as opções presentes no Cadastro 
Nacional de Estabelecimentos de Saúde (2019), a saber: "Centros de especialidades", "Consultórios isolados", "Hospitais gerais", "Policlínicas" e "Unidades de diagnose e terapia". Para as classes de faturamento (questão ordinal fechada) empregaram-se as opções utilizadas pela Agência Nacional de Vigilância Sanitária (2019): "Microempresa" (faturamento igual ou inferior a $\mathrm{R} \$ 360.000,00$ ), "Empresa de pequeno porte" (igual ou inferior a $\mathrm{R} \$ 4.800 .000,00 \mathrm{e}$ superior a $\mathrm{R} \$ 360.000,00$ ), "Empresa de médio porte I" (igual ou inferior a $\mathrm{R} \$ 6.000 .000,00 \mathrm{e}$ superior a $\mathrm{R} \$ 4.800 .000,00$ ), "Empresa de médio porte II" (igual ou inferior a $\mathrm{R} \$ 20.000 .000,00$ e superior a $R \$ 6.000 .000,00$ ), "Empresa de grande porte I" (igual ou inferior a $R \$$ $50.000 .000,00$ e superior a $\mathrm{R} \$ \mathbf{2 0 . 0 0 0 . 0 0 0 , 0 0 )}$ e, "Empresa de grande porte II" (superior a R\$ $50.000 .000,00)$.

Uma vez que, pelo teste de Kolmogorov-Smirnov, apenas $13,64 \%$ das variáveis submetidas aos respondentes não apresentaram significantes desvios em relação à distribuição normal, optou-se por empregar, como principal método de análise, a análise de correspondência múltipla, que prescinde deste pressuposto (PAULA, et al., 2010). A opção por este método também é amparada no fato de que as variáveis capturam um atributo essencialmente qualitativo (percepção de intensidade). A partir daí o protocolo norteador da pesquisa esquematizou-se conforme mostrado no Quadro 4:

Quadro 4-Protocolo de análise

\begin{tabular}{|c|c|c|c|}
\hline Etapas & Objetivos & \multicolumn{2}{|c|}{ Procedimentos estatísticos e suporte teórico } \\
\hline 1 & $\begin{array}{l}\text { Prover uma visão geral das características } \\
\text { das empresas respondentes. }\end{array}$ & \multicolumn{2}{|c|}{$\begin{array}{l}\text { Médias, desvios padrão e frequências } \\
\text { (COOPER; SCHINDLER, 2003; HAIR JR, et al., } \\
\text { 2005) }\end{array}$} \\
\hline 2 & $\begin{array}{l}\text { Avaliar a confiabilidade interna dos } \\
\text { conjuntos de questões submetidas aos } \\
\text { respondentes. }\end{array}$ & \multicolumn{2}{|c|}{$\begin{array}{l}\text { Alfa de Cronbach (MAROCO; GARCIA- } \\
\text { MARQUES, 2006) }\end{array}$} \\
\hline 3 & $\begin{array}{l}\text { Agrupar os resultados das variáveis de GC, } \\
\text { IN, CO, SI e PI. }\end{array}$ & \multicolumn{2}{|c|}{ Percentil (FÁVERO, et al., 2009) } \\
\hline 4 & Recategorizar as variáveis agrupadas. & \multicolumn{2}{|c|}{$\begin{array}{l}\text { Abaixo de } 33 \% \text { = Baixo; } \\
\text { Entre } 33,01 \% \text { e } 66 \%=\text { Médio; } \\
\text { Acima de } 66 \% \text { = Alto. }\end{array}$} \\
\hline 5 & $\begin{array}{l}\text { Avaliara as diferenças entre pontos } \\
\text { medianos das variáveis numéricas com as } \\
\text { características de GC, IN, CO, SI e PI. }\end{array}$ & \multicolumn{2}{|c|}{ H de Kruskal-Wallis, chi-quadrado (FIELD, 2009) } \\
\hline 6 & $\begin{array}{l}\text { Verificar a independência entre as } \\
\text { variáveis de GC, IN, CO, SI, PI e grupos de } \\
\text { faturamento. }\end{array}$ & \multicolumn{2}{|c|}{ Chi-quadrado (LOMBARDO; BEH, 2010) } \\
\hline 7 & $\begin{array}{l}\text { Determinar o número de dimensões a } \\
\text { serem analisadas. }\end{array}$ & \multirow{5}{*}{ 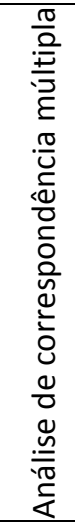 } & Eingenvalues e inércia (CARVALHO, 2008) \\
\hline 8 & $\begin{array}{l}\text { Avaliar a confiabilidade do conjunto de } \\
\text { variáveis escolhidas para serem } \\
\text { representadas nas dimensões. }\end{array}$ & & $\begin{array}{l}\text { Alfa de Cronbach dos eingenvalues } \\
\text { médios (CARVALHO, 2008; MAROCO; } \\
\text { GARCIA-MARQUES, 2006) }\end{array}$ \\
\hline 9 & $\begin{array}{l}\text { Avaliar a variância explicada para as } \\
\text { dimensões. }\end{array}$ & & $\begin{array}{l}\text { Percentual da inércia de cada dimensão } \\
\text { em relação ao total das inércias (FÁVERO, } \\
\text { et al., 2009) }\end{array}$ \\
\hline 10 & Determinar as coordenadas dos eixos. & & $\begin{array}{l}\text { Frequências, massas e eingenvalues das } \\
\text { categorias; escores (FÁVERO, et al., 2009) }\end{array}$ \\
\hline 11 & $\begin{array}{l}\text { Visualizar a distribuição do conjunto de } \\
\text { pontos das categorias. }\end{array}$ & & $\begin{array}{l}\text { Gráfico da quantificação das categorias } \\
\text { (CARVALHO, 2008; FÁVERO, et al., 2009) }\end{array}$ \\
\hline 12 & $\begin{array}{l}\text { Avaliar a intensidade de associação das } \\
\text { categorias. }\end{array}$ & \multicolumn{2}{|c|}{$\begin{array}{l}\text { Coeficiente de correlação de Pearson (FIELD, } \\
\text { 2009) }\end{array}$} \\
\hline
\end{tabular}

Fonte: compilado pelos autores (2019) 
Utilizaram-se os softwares PASW Statistics $18{ }^{\circledR}$ e Microsoft Office Excel $2007{ }^{\circledR}$, considerando, nos devidos testes, um nível de significância esperado de 0,05.

\section{ANÁLISE E DISCUSSÃO DE RESULTADOS}

As empresas que responderam ao questionário informaram terem sido estabelecidas há 9,71 anos, com desvio padrão de 8,32, sendo que a mais antiga foi fundada em 1961 e a mais recente, em 2013. Quanto ao número de funcionários, 38,7\% responderam possuir de um a nove colaboradores; $30,6 \%$, de 10 a $49 ; 11,3 \%$ de 50 a $149 ; 6,5 \%$ de 150 a 249, e; $12,9 \%$, afirmaram contar com um número superior a 249 funcionários. Em relação ao faturamento, $19,4 \%$ registraram serem empresas de pequeno porte; $41,9 \%$, empresas de médio porte I; $21 \%$ empresas de médio porte II e; $17,7 \%$ se identificaram como empresas de grande porte I. Quanto a principal atividade, $14,5 \%$ informaram serem centros de especialidades; $41,9 \%$, consultórios isolados; $9,7 \%$, hospitais gerais; $21 \%$ policlínicas e; $12,9 \%$, unidades de diagnose e terapia.

Devido o grande número de questões, em relação ao número relativamente reduzido de respostas, optou-se por agrupa-las pelos construtos de GC, IN, CO, SI e PI e proceder às análises subsequentes a partir desta configuração. Inicialmente, há que se verificar se existe confiabilidade no agrupamento das variáveis, empregando-se o alfa de Cronbach. Para a GC, o alfa atingiu 0,931; para IN, 0,866; CO, 0,667; para SI, 0,842 e; PI, 0,870. Neste sentido, com exceção do agrupamento de $\mathrm{CO}$, os valores indicam, no mínimo, apropriada confiabilidade do instrumento de pesquisa (HORA, MONTEIRO e ARICA, 2010). Porém, há que se ponderar que um valor acima de 0,6 para o alfa de Cronbach, em Ciências Sociais, já pode ser considerado aceitável (MAROCO e GARCIA-MARQUES, 2006). A partir daí, as respostas foram agrupadas em duas etapas: (1a) obteve-se a frequência percentual de cada grupo e; (2aㅡ) as respostas agrupadas pela frequência percentual foram classificadas, arbitrariamente, em 'Baixo', quando este resultado não atingiu 70\%; 'Alto' quando foi igual ou superior a $90 \%$ e; 'Médio' quando esteve entre estas faixas. $O$ critério de escolha das classes percentuais foi que as mesmas pudessem manter o maior equilíbrio em relação ao número de casos entre as faixas. Desta forma, as respostas ficaram distribuídas conforme mostra a Tabela 1:

Tabela 1 - Frequência de percepções de GC, CO, IN, SI e PI (\%)

\begin{tabular}{l|c|c|c|c|c}
\hline Percepção & GC & CO & IN & SI & PI \\
\hline Baixo & 4,8 & 14,5 & 17,7 & 25,8 & 16,1 \\
\hline Médio & 80,6 & 46,8 & 74,2 & 54,8 & 50,0 \\
\hline Alto & 14,5 & 38,7 & 8,1 & 19,4 & 33,9 \\
\hline
\end{tabular}

Fonte: Dados da pesquisa (2019)

As relações entre as características dos estabelecimentos respondentes e a intensidade com que adotam os elementos de GC, IN, CO, SI e PI indicam que, quanto ao tempo de existência não é possível afirmar que esta variável apresenta diferenças estatisticamente significativas nos grupos de $\mathrm{GC}(\mathrm{H}(2)=1,373$, p-valor $<0,503)$ e $\mathrm{IN}(\mathrm{H}(2)=$ $2,619, p$-valor $<0,270)$. O mesmo não se pode afirmar em relação aos grupos de $\mathrm{CO}(\mathrm{H}(2)=$ 12,909, p-valor < 0,002), SI (H(2) =6,047, p-valor <0,047) e, PI $(H(2)=4,226, p$-valor < 0,040). Já em relação ao número de colaboradores é possível afirmar que estabelecimentos com números diferentes de colaboradores não se distinguem pela intensidade de percepção das práticas de $\mathrm{GC}\left(\mathrm{X}^{2}(8)=10,877\right.$, $\mathrm{p}$-valor $\left.<0,209\right)$ e $\mathrm{CO}\left(\mathrm{X}^{2}(8)=11,631\right.$, $\mathrm{p}$-valor $\left.<0,168\right)$. Porém, no IN $\left(X^{2}(8)=17,297\right.$, p-valor $\left.<0,027\right)$, SI $\left(X^{2}(8)=31,001\right.$, p-valor $\left.<0,000\right)$ e, PI $\left(X^{2}(8)=27,1669\right.$, $p$-valor $<0,001)$, verificaram-se diferenças significativas. Quanto às categorias de faturamento, existem expressivas distinções na forma como percebem a GC $\left(X^{2}(6)=15,502\right.$, $p$-valor $\left.<0,017\right)$, 
CO $\left(X^{2}(6)=13,227\right.$, p-valor $\left.<0,040\right)$, IN $\left(X^{2}(6)=16,112\right.$, p-valor $\left.<0,013\right)$, SI $\left(X^{2}(6)=38,113, p\right.$ valor $<0,000)$ e PI $\left(X^{2}(6)=24,258, p\right.$-valor $\left.<0,000\right)$. Finalmente, é possível afirmar que 0 segmento de atuação não distingue as empresas quanto à percepção de $G C\left(X^{2}(8)=9,745\right.$, pvalor $<0,283)$, $C O\left(X^{2}(8)=10,604\right.$, $p$-valor $\left.<0,225\right)$, IN $\left(X^{2}(8)=6,146\right.$, $p$-valor $\left.<0,631\right)$ e $\operatorname{PI}\left(X^{2}(8)\right.$ $=10,416, p$-valor $<0,237)$, porém, esta diferença é observada para os $S I\left(X^{2}(8)=23,038, p\right.$ valor $<0,003)$.

Quanto à existência de grupos que se destacam pelas diferentes concepções de GC, IN, $\mathrm{CO}, \mathrm{SI}$ e PI, entre si, a Tabela 2 mostra que a intensidade de percepção em um dos grupos se reflete nos demais:

Tabela 2 - Diferenças entre grupos

\begin{tabular}{c|l|c|c|c|c}
\hline Grupo & Estatística & CO & IN & SI & PI \\
\hline \multirow{2}{*}{ GC } & $X^{2}(4)$ & 23,047 & 46,516 & 35,413 & 20,672 \\
\cline { 2 - 6 } & $p$-valor & 0,000 & 0,000 & 0,000 & 0,000 \\
\hline \multirow{2}{*}{ CO } & $X^{2}(4)$ & & 15,153 & 19,756 & 12,774 \\
\cline { 2 - 6 } & $p$-valor & & 0,004 & 0,001 & 0,012 \\
\hline \multirow{2}{*}{ IN } & $X^{2}(4)$ & 15,153 & & 43,255 & 32,026 \\
\cline { 2 - 6 } & $p$-valor & 0,004 & & 0,000 & 0,000 \\
\hline \multirow{2}{*}{ SI } & $X^{2}(4)$ & 19,756 & 43,255 & & 39,325 \\
\cline { 2 - 6 } & p-valor & 0,001 & 0,000 & & 0,000 \\
\hline \multicolumn{4}{|l|}{ Fonte: Dados da pesquisa (2019) }
\end{tabular}

Há que se relatar o fato de que em todos os cruzamentos de dados realizados (aferidos pelo $\mathrm{X} 2$ ), devido ao elevado número de categorias em relação à quantidade de respostas, sempre se registraram células com menos de cinco casos - comprometendo a robustez do teste. Mesmo assim, assume-se a existência de grupos distintos de empresas quanto às suas características de ano de fundação, número de colaboradores e faturamento, em relação às GC, IN, CO, SI e PI. No intuito de reduzir o número de variáveis de caracterização da amostra, buscou-se identificar aquelas que podem representar, de alguma forma ou de outra, os mesmos elementos. Desta forma, ao utilizar o teste do X2 entre estas variáveis, percebe-se que empresas com maior tempo de existência também são aquelas que mais faturam $\left(X^{2}(12)=\right.$ 15,180 , p-valor $<0,283$ ) e que estas também são as que possuem o maior número de colaboradores $\left(X^{2}(12)=75,629, p\right.$-valor $\left.<0,000\right)$. Assim sendo, assume-se que 'colaboradores' e 'faturamento' estejam representando o mesmo fenômeno e, desta forma, eliminou-se das análises subsequentes a variável referente a número de colaboradores.

No intuito de tornar explícitas as diferenças detectadas até o momento, utilizou-se da análise de correspondência múltipla. Este procedimento identifica padrões de associação entre varáveis categóricas, distribuindo-as em um plano de $n$ dimensões, a partir da variabilidade dos dados explicada em cada dimensão (inércias). Inicialmente, há que se estabelecer o número mínimo aceitável de dimensões. Uma das formas de estabelecimento deste número é avaliar os alfas de Cronbach, os eingenvalues e as inércias de cada uma das 15 possíveis dimensões. A Tabela 3 mostra estes valores: 
Tabela 3 - Eigenvalues e inércias do total de dimensões

\begin{tabular}{|c|c|c|c|c|c|c|c|c|c|c|c|c|c|c|c|}
\hline Dimensões & 1 & 2 & 3 & 4 & 5 & 6 & 7 & 8 & 9 & 10 & 11 & 12 & 13 & 14 & 15 \\
\hline Alfas & 0,86 & 0,73 & 0,35 & 0,20 & $-0,01$ & $-0,09$ & $-0,24$ & $-0,46$ & $-0,85$ & $-1,40$ & $-1,73$ & $-2,81$ & $-3,17$ & $-3,96$ & $-5,54$ \\
\hline Eigenvalues & 3,86 & 2,66 & 1,42 & 1,20 & 0,99 & 0,93 & 0,83 & 0,72 & 0,58 & 0,46 & 0,40 & 0,29 & 0,27 & 0,23 & 0,17 \\
\hline Inércias & 0,55 & 0,38 & 0,20 & 0,17 & 0,14 & 0,13 & 0,12 & 0,10 & 0,08 & 0,07 & 0,06 & 0,04 & 0,04 & 0,03 & 0,02 \\
\hline
\end{tabular}

Fonte: Fonte: Dados da pesquisa (2019)

É notável que somente as inércias das duas primeiras dimensões representam 43,42\% do total das 15 dimensões - indicando sua representatividade. Além disto, destaca-se que para a primeira dimensão, o alfa de Cronbach apresenta uma elevada confiabilidade, enquanto que, para a segunda, é possível considera-la, no mínimo, aceitável. Desta maneira, assume-se que as variáveis possam ser adequadamente distribuídas em um plano bidimensional. Assim sendo, plotando-se as medidas de discriminação em um plano com duas dimensões obteve-se a Figura 1 a seguir:

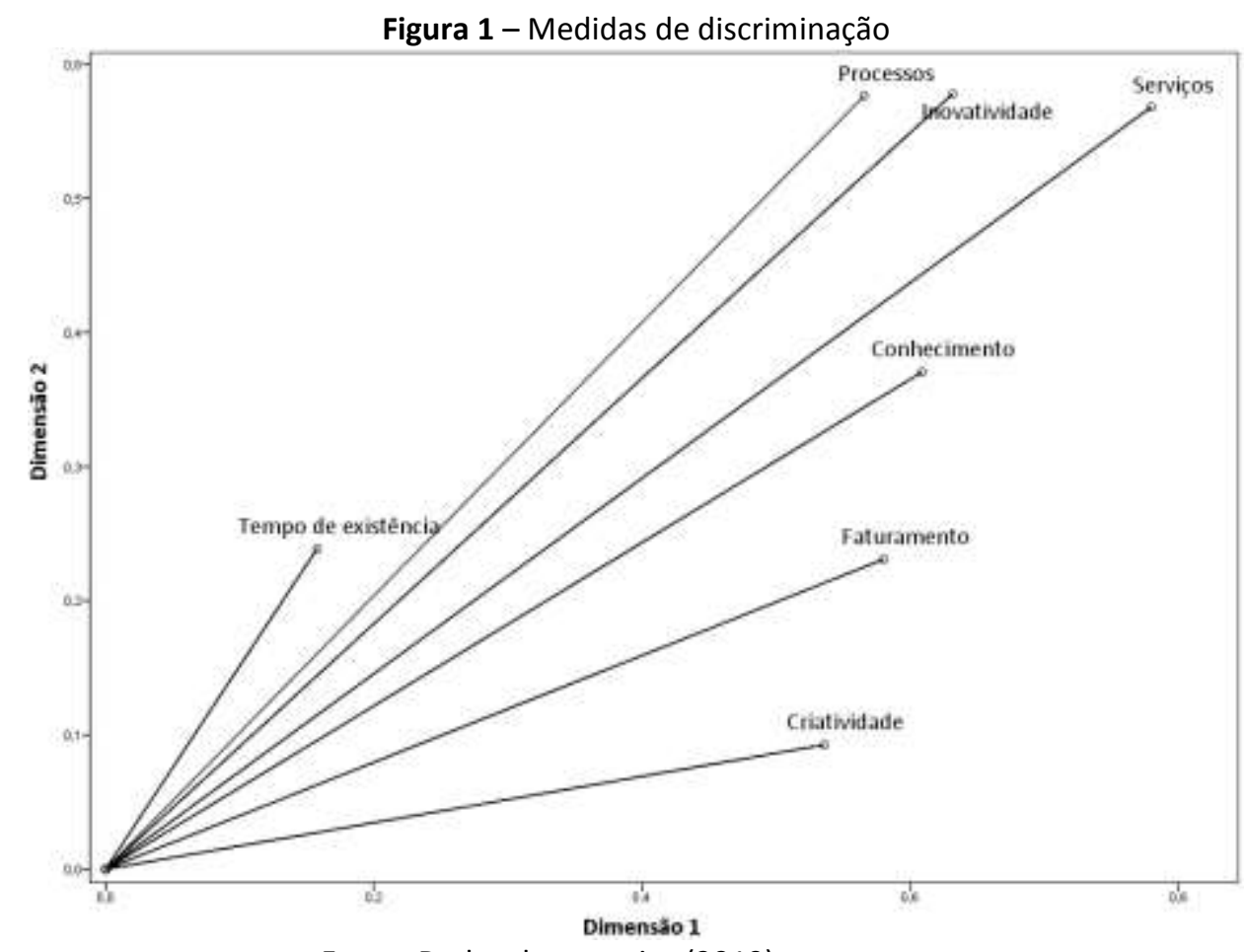

Fonte: Dados da pesquisa (2019)

A Figura 1 mostra que, por estarem mais distante do ponto de origem $(0,0)$, os grupos de IN, SI e PI são os mais representativos nas duas dimensões, seguido por GC. Por outro lado, nota-se que os grupos de tempo de existência e CO mostram-se mais representativos em apenas uma, do que ambas as dimensões.

Para a distribuição das categorias de cada grupo de variáveis analisadas nas duas dimensões, avaliaram-se as frequências, massas e inércias mostradas na Tabela 4 a seguir: 
Tabela 4 - Frequências, massas e inércias das categorias

\begin{tabular}{|c|c|c|c|c|}
\hline \multicolumn{2}{|c|}{ Categorias } & Inércias & Massas & Frequências \\
\hline \multirow{3}{*}{ 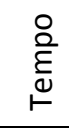 } & Novas & 0,104 & 0,039 & 17 \\
\hline & Intermediárias & 0,090 & 0,053 & 23 \\
\hline & Antigas & 0,092 & 0,051 & 22 \\
\hline \multirow{4}{*}{ 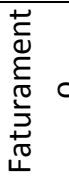 } & Pequena & 0,115 & 0,028 & 12 \\
\hline & Média & 0,083 & 0,060 & 26 \\
\hline & Média-grande & 0,113 & 0,030 & 13 \\
\hline & Grande & 0,118 & 0,025 & 11 \\
\hline \multirow{3}{*}{$\mathrm{GC}$} & Baixa & 0,136 & 0,007 & 3 \\
\hline & Média & 0,028 & 0,115 & 50 \\
\hline & Alta & 0,122 & 0,021 & 9 \\
\hline \multirow{3}{*}{$\mathrm{CO}$} & Baixa & 0,122 & 0,021 & 9 \\
\hline & Média & 0,076 & 0,067 & 29 \\
\hline & Alta & 0,088 & 0,055 & 24 \\
\hline \multirow{3}{*}{ IN } & Baixa & 0,118 & 0,025 & 11 \\
\hline & Média & 0,037 & 0,106 & 46 \\
\hline & Alta & 0,131 & 0,012 & 5 \\
\hline \multirow{3}{*}{ SI } & Baixa & 0,106 & 0,037 & 16 \\
\hline & Média & 0,065 & 0,078 & 34 \\
\hline & Alta & 0,115 & 0,028 & 12 \\
\hline \multirow{3}{*}{ PI } & Baixa & 0,120 & 0,023 & 10 \\
\hline & Média & 0,071 & 0,071 & 31 \\
\hline & Alta & 0,094 & 0,048 & 21 \\
\hline
\end{tabular}

Fonte: Dados da pesquisa (2019)

As massas indicam que, quanto ao tempo de existência, as empresas mais longevas apresentam maior influência sobre as mais novas; enquanto que, nas demais categorias, as categorias que representam o intermédio, são as mais influentes. As inércias, por sua vez, mostram que a capacidade de explicação da variância total. Neste sentido, nota-se que em relação ao tempo de existência, as empresas mais jovens apresentam maior capacidade de esclarecer a variância encontrada no grupo; para o grupo faturamento, são as empresas que se classificaram na categoria de maior faturamento; para os grupos de GC, $\mathrm{CO}$ e $\mathrm{PI}$, aquelas com baixa percepção possuem maior capacidade de explicação da variância; enquanto que nos grupos de IN e SI, são as que se percebem como mais inovadoras.

Para o estabelecimento das coordenadas de cada categoria, em um plano bidimensional, aplicou-se a normalização simétrica que resultou nos seguintes escores, distribuídos na Figura 2: 
Figura 2 - Coordenadas das categorias

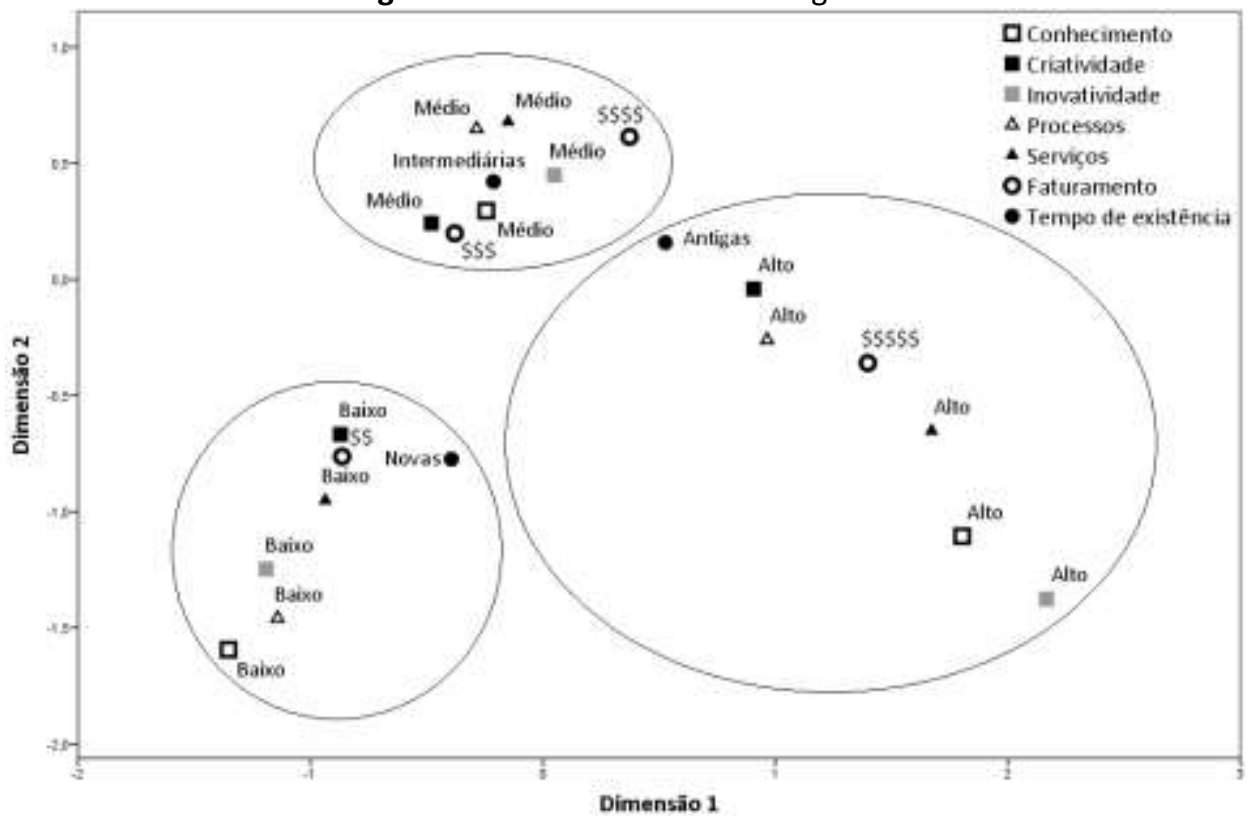

Fonte: Fonte: Dados da pesquisa (2019).

Notam-se três agrupamentos distintos, nos quais, basicamente, torna-se explícito o fato de que os empreendimentos mais longevos também são aqueles em que a GC, CO e IN são percebidas como sendo mais intensas - estas empresas também se assemelham quanto ao fato de serem as que mais inovam e mais faturam. O outro extremo é formado por aquelas com menor tempo de existência, nas quais a GC, CO e IN são percebidas com menos intensidade, sendo que os aspectos de inovação e o faturamento também são, comparativamente, menores.

É possível destacar, numericamente, a associação entre os elementos analisados a partir do coeficiente de correlação de Pearson aplicado às variáveis transformadas, conforme visualizado na Tabela 5:

Tabela 5 - Correlações das variáveis transformadas

\begin{tabular}{|c|c|c|c|c|c|c|c|}
\hline Variável & Estatística & Faturamento & GC & $\mathrm{CO}$ & IN & SI & PI \\
\hline \multirow{2}{*}{$\begin{array}{l}\text { Tempo de } \\
\text { existência }\end{array}$} & $r$ & 0,358 & 0,137 & 0,356 & 0,118 & 0,251 & 0,239 \\
\hline & $p$-valor & 0,004 & 0,289 & 0,005 & 0,363 & 0,049 & 0,062 \\
\hline \multirow{2}{*}{ Faturamento } & $r$ & & 0,422 & 0,429 & 0,454 & 0,694 & 0,557 \\
\hline & $p$-valor & & 0,001 & 0,000 & 0,000 & 0,000 & 0,000 \\
\hline \multirow{2}{*}{$\mathrm{GC}$} & $r$ & 0,422 & & 0,541 & 0,690 & 0,649 & 0,448 \\
\hline & $p$-valor & 0,001 & & 0,000 & 0,000 & 0,000 & 0,000 \\
\hline \multirow{2}{*}{$\mathrm{CO}$} & $r$ & 0,429 & 0,541 & & 0,488 & 0,558 & 0,428 \\
\hline & $p$-valor & 0,000 & 0,000 & & 0,000 & 0,000 & 0,001 \\
\hline \multirow{2}{*}{ IN } & $r$ & 0,454 & 0,690 & 0,488 & & 0,655 & 0,539 \\
\hline & p-valor & 0,000 & 0,000 & 0,000 & & 0,000 & 0,000 \\
\hline \multirow{2}{*}{ SI } & $r$ & 0,694 & 0,649 & 0,558 & 0,655 & & 0,612 \\
\hline & $p$-valor & 0,000 & 0,000 & 0,000 & 0,000 & & 0,000 \\
\hline
\end{tabular}

As correlações das variáveis transformadas tornam explícitas algumas evidências. A primeira delas é o fato de que o tempo de existência das empresas apresenta uma fraca 
associação (nos casos em que esta associação é confirmada) com as demais variáveis. Isto pode indicar que, na amostra estudada, a GC, CO e IN não são condições que se desenvolvem organicamente ao longo do tempo, mas possivelmente implementadas de forma intencional. Interessante é o poder de explicação que os SI $(48,16 \%)$ e $\mathrm{PI}(31,02 \%)$ exercem sobre o faturamento. Outro fato que chama a atenção é que a variação dos SI está fortemente associada ao GC $(42,12 \%)$, CO $(31,13 \%)$ e IN $(42,9 \%)$ - por sua vez, a variação da GC explica $29,26 \%$ da CO e 47,61\% da IN. Também são óbvias as explicações de 42,9\% dos SI e de 29,05\% dos PI pelo IN. Finalmente, nota-se a existência de associação entre os SI e PI nas empresas pesquisadas: a variação de uma delas explica $37,45 \%$ da outra, indicando que a oferta de produtos/serviços inovadores está relacionada com o desenvolvimento de processos também inovadores.

É necessário que se confronte os resultados encontrados com estudos anteriores. Quanto às relações encontradas junto ao aspecto de faturamento, Hanley (2014) coloca que medidas verdadeiramente sustentáveis de valor para uma solução de GC deve se relacionar diretamente com este elemento. Já Nowacki e Bachnik (2016), em uma pesquisa conduzida junto a gerentes de 608 empresas polonesas dos ramos de indústria, comércio e serviços, encontraram forte associação entre a intensidade de práticas de GC, IN e faturamento. $\mathrm{O}$ mesmo resultado foi encontrado junto a 52 empresas de base tecnológica paranaenses (BEZERRA; QUANDT, 2013). Também Bezerra e Wronski (2016) encontraram associação entre GC, IN, CO e faturamento (em uma pesquisa conduzida entre 60 bares, restaurantes e casas noturnas de Curitiba - PR), da mesma forma que Bezerra e Guimarães (2017) em 60 agências de publicidade paranaenses.

Já para as associações que envolvem GC, CO e IN, Anderson, Potocnik e Zhou (2014) ressaltam o caráter indissociável entre elas, porém sugerem estudos que possam teorizar estas relações. Por sua vez, Ferguson (2014) em um estudo multicaso realizado em quatro indústrias britânicas, nota que a expectativa sobre a inovação é mais acentuada naquelas que atuam de forma criativa e absorvem o conhecimento a partir de relações com universidades. Uma pesquisa realizada entre 43 coordenadores de comunidades de prática de onze indústrias públicas e privadas, Swan, Scarbrough e Ziebro (2015) mostram que organizações mais criativas experimentam mais compartilhamento do conhecimento e, como resultado, também são mais inovadoras.

\section{CONSIDERAÇÕES FINAIS}

Julga-se importante resgatar o problema que norteou a presente pesquisa: as relações existentes entre $\mathrm{GC}, \mathrm{CO}$, IN encontram-se associadas ao desempenho inovador e no faturamento das empresas do segmento de saúde no município de Curitiba - PR? A resposta a este problema é: na amostra estudada, a GC, CO e IN associam-se entre si e apresentam relação tanto com o desempenho inovador (SI e PI) como com o faturamento dos estabelecimentos pesquisados. Estas relações ocorrem de tal forma que, as percepções mais intensas de GC, CO e IN ocorrem nos estabelecimentos que possuem tanto produtos/serviços (SI) como processos (PI) mais inovadores e, maior faturamento. Porém, há que se levar em consideração que o tempo de existência das empresas também apresentou a mesma relação com o desempenho inovador e, consequente, faturamento. Os resultados apresentados mostram-se inéditos ao expressarem a indissociabilidade das GC, CO, IN, SI e PI, diferentemente de estudos anteriores que apresentavam associações pareadas destes elementos (CHRISTOPHER; TANWAR, 2012; CAMELO-ORDAZ et al., 2011; CLAUß, 2012; DAVIS; EISENHARDT, 2011), bem como sugere que o conjunto destas relações é compatível com o desempenho financeiro.

Perspectivas em Gestão \& Conhecimento, João Pessoa, v. 9, n. 2, p. 56-84, maio/ago. 2019. 
Apesar do problema de pesquisa ter sido respondido, a pesquisa não se encontra isenta de limitações - as quais oferecem oportunidades para pesquisas futuras. A primeira delas relaciona-se ao reduzido número de respostas em relação ao elevado número de questões. Esta situação pode estar relacionada a vieses junto ao alfa de Cronbach. Assim sendo, é premente realizar novos estudos no sentido de (1) obter uma amostra maior de respondentes e, a partir daí, (2) buscar reduzir o número de questões sem que ocorra perda semântica significativa dos construtos. Além disto, a não normalidade registrada na maioria das variáveis conduziu o emprego de um método de análise que, se por um lado, foi capaz de tornar explícitas as relações buscadas, por outro, não se mostrou apropriado para isolar o efeito das GC, CO e IN no desempenho inovador (SI e PI) e faturamento, visto que também o tempo de existência relacionou-se com estes elementos. Esta situação leva a, pelo menos, três indagações: (1) é possível que as GC, CO e IN se organizem organicamente na proporção em que as empresas vão se tornando mais maduras?; (2) na medida em que as organizações vão se tornando mais longevas, isto requer que as GC, CO e IN sejam estabelecidas de maneira mais intensa e/ou formal - até mesmo como forma de as manterem no mercado?; (3) é coerente assumir que o desempenho inovador vai ocorrer, de qualquer forma, quando do amadurecimento temporal destas empresas? Estas perguntas sugerem posteriores pesquisas que possam determinar de que forma se estabelecem as bases de GC, CO e IN em empresas, bem como seu desempenho inovador, ao longo do tempo.

Seja como for, os resultados encontrados podem apresentar contribuições acadêmicas e gerenciais. No campo acadêmico, estabelecem-se indícios para a integração teórica entre GC, $\mathrm{CO}$, IN e desempenho inovador. Neste sentido, há que se aprofundar em pesquisas que tornem explícito a maneira como estas relações ocorrem a partir dos processos organizacionais, estabelecidos na plenitude dos níveis hierárquicos das empresas. No campo gerencial, evidenciam-se os elementos constitutivos do desempenho inovador a partir do estabelecimento de condições organizacionais capazes de conduzir o conhecimento, a criatividade e a inovação a níveis superiores de serviços e processos inovadores (acompanhados do faturamento), essenciais em contextos socioeconômicos nos quais a competitividade é uma característica presente.

\section{REFERÊNCIAS}

AGÊNCIA NACIONAL DE VIGILÂNCIA DE SANITÁRIA. Como é feita a classificação de uma empresa segundo seu porte junto à Anvisa? Porte da Empresa, 2019. Disponível em: http://portal.anvisa.gov.br/porte-de-empresa. Acesso em: 9 abr. 2019.

ALBERS, A. et al. Connected creativity - a human centered community innovation platform in the context of product generation engineering. Design Science, Cambridge, v. 4, n. 6, p. 1-26, february 2018. Disponível em: https://www.cambridge.org/core/services/aop-cambridgecore/content/view/69DA9C3DE303A8E56E1860D1C3C69AB7/S2053470118000021a.pdf/divclass-title-connected-creativity-a-human-centered-community-innovation-platform-in-thecontext-of-product-generation-engineering-div.pdf. Acesso em: 6 jul. 2019.

ALVES, M. F.R.; GALINA, S. V.R.; DOBELIN, S. Literature on organizational innovation: past and future. Innovation \& Management Review, v. 15, n. 1, p. 2-19, 2018. Disponível em: https://www.emeraldinsight.com/doi/abs/10.1108/INMR-01-2018-001. Acesso em: 6 jul. 2019. 
AMABILE, T. M. How to kill creativity. Harvard Business Review, v. 76, n. 5, p. 77-87, september-october 1998. Disponível em: https://hbr.org/1998/09/how-to-kill-creativity. Acesso em: 6 jul. 2019.

AMABILE, T. M. A model of creativity and innovation in organizations. In: STAW, B. M.; SUTTON, R. I. Research in Organizational Behavior. [S.I.]: Elsevier, v. 22, p. 123-167, 2000.

AMABILE, T. M. et al. Assessing the work environment for creativity. The Academy of Management Journal, v. 39, n. 5, p. 1154-1184, 1996. Disponível em: https://journals.aom.org/doi/10.5465/256995. Acesso em: 6 jul. 2019.

AMORIM, M. C.S.; FREDERICO, R. Criatividade, inovação e controle nas organizações. Revista de Ciências Humanas, Florianópolis, v. 42, n. 1 e 2, p. 75-89, abril-outubro 2008. Disponível em: https://periodicos.ufsc.br/index.php/revistacfh/article/download/14520/13295. Acesso em: 6 jul. 2019.

ANDERSON, N.; POTOCNIK, K.; ZHOU, J. Innovation and creativity in organizations: a state-ofthe-science review, prospective commentary, and guiding framework. Journal of Management, v. 40, n. 5, p. 1297-1333, 2014. Disponível em: https://journals.sagepub.com/doi/10.1177/0149206314527128. Acesso em: 6 jul. 2019.

ANDRADE, M. V. et al. Desafios do sistema de saúde brasileiro. In: DI NEGRI, J. A.; ARAÚJO, B. C.P.O.; BACELETTE, R. G. Desafios da nação: artigos de apoio. Brasília: Instituto de Pesquisa Econômica Aplicada, v. 2, p. 356-414, 2018.

ANTONELLI, C. Knowledge properties and economic policy: a new look. Science and Public Policy, v. 45, n. 2, p. 151-158, april 2018. Disponível em: https://academic.oup.com/spp/article/45/2/151/4992964. Acesso em: 6 jul. 2019.

AUDRETSCH, D. B.; LINK, A. N. Innovation capital. The Journal of Technology Transfer, v. $43, n$. 6, p. 1760-1767, december 2018.2 Disponível em: https://link.springer.com/article/10.1007/s10961-018-9700-6. Acesso em: 6 jul. 2019.

AZEVEDO, C. S.; BRAGA NETO, F. C.; SA, M. C. Indivíduo e a mudança nas organizações de saúde: contribuições da psicossociologia. Cadernos de Saúde Pública, Rio de Janeiro, v. 18, n. 1, p. 235-247, jan./fev. 2002. Disponível em: http://www.scielo.br/scielo.php?pid=S0102311X2002000100024\&script=sci abstract\&tlng=pt. Acesso em: 6 jul. 2019.

BAHIA, L. Trinta anos de Sistema Único de Saúde (SUS): uma transição necessária, mas insuficiente. Cadernos de Saúde Pública, Rio de Janeiro, v. 34, n. 7, p. 1-16, agosto 2018. Disponivel em: $\quad$ http://www.scielo.br/scielo.php?script=sci abstract\&pid=S0102311X2018000700401\&lng=pt\&nrm=iso\&tlng=pt. Acesso em: 6 jul. 2019.

BAUM, C. F.; LOOF, H.; NABAVI, P. Innovation strategies, external knowledge and productivity growth. Industry and Innovation, v. 26, n. 3, p. 348-367, august 2019. Disponível em: https://www.tandfonline.com/doi/abs/10.1080/13662716.2018.1499502. Acesso em: 6 jul. 2019.

BEZERRA, C. A.; GUIMARÃES, A. J.R. Mineração de texto aplicada às publicações científicas sobre gestão do conhecimento no período de 2003 a 2012. Perspectivas em Ciência da Informação, v. 19, n. 2, p. 131-146, 2014 . Disponível em: http://www.scielo.br/pdf/pci/v19n2/10.pdf. Acesso em: 6 jul. 2019.

BEZERRA, C. A.; GUIMARÃES, A. J.R. O desempenho inovador de agências de publicidade e sua relação com a gestão do conhecimento e condições organizacionais de inovatividade e criatividade. Perspectivas em Gestão \& Conhecimento, João Pessoa, v. 7, n. 1, p. 70-97, 
jan/jun

2017.

Disponível

em:

http://www.periodicos.ufpb.br/index.php/pgc/article/view/26315/17909. Acesso em: 6 jul. 2019.

BEZERRA, C. A.; QUANDT, C. O. Relações entre gestão do conhecimento, faturamento e número de funcionários em empresas graduadas por incubadoras. Revista de Gestão, v. 20, n. 4, p. 537-556, 2013. Disponível em: http://www.revistas.usp.br/rege/article/view/99939. Acesso em: 6 jul. 2019.

BEZERRA, C. A.; WRONSKI, J. L.M. Inovatividade, criatividade e gestão do conhecimento em bares, restaurantes e casas noturnas: um estudo em estabelecimentos de Curitiba - PR. Revista Brasileira de Pesquisa em Turismo, São Paulo, v. 10, n. 1, p. 18-43, jan/abr 2016. Disponível em: http://www.scielo.br/scielo.php?pid=S198261252016000100018\&script=sci abstract\&tlng=pt. Acesso em: 6 jul. 2019.

BISCOTTI, A. M.; D'AMICO, E.; MONGE, F. Do environmental management systems affect the knowledge management process? The impact on the learning evolution and the relevance of organizational context. Journal of Knowledge Management, v. 22, n. 3, p. 603-620, 2018. Disponível em: https://www.emeraldinsight.com/doi/abs/10.1108/JKM-08-2017-0344. Acesso em: 6 jul. 2019.

BLOODGOOD, J. M. Knowledge acquisition and firm competitiveness: the role of complements and knowledge source. Journal of Knowledge Management, v. 23, n. 1, p. 46-66, 2019. Disponível em: https://www.emeraldinsight.com/doi/abs/10.1108/JKM-09-2017-0430?af=R. Acesso em: 6 jul. 2019.

BOISOT, M. H. Knowledge assets: securing competitive advantage in the information economy. Oxford: Oxford University Press, 1999.

BOLDEN, R.; O'REGAN, N. Leadership and creativity in public services: an interview with Lord Michael Bichard, Chair of the National Audit Office. Journal of Management Inquiry, v. 27, n. 1, p. 47-51, january 2018. Disponível em: https://journals.sagepub.com/doi/10.1177/1056492616688088. Acesso em: 6 jul. 2019.

BURGER, F. et al. Barreiras, elementos dificultadores e fatores críticos na implementação da Gestão do Conhecimento: uma revisão da literatura. Perspectivas em Gestão \& Conhecimento, João Pessoa, v. 8, n. 2, p. 43-61, mai./ago. 2018. Disponível em: http://www.periodicos.ufpb.br/index.php/pgc/article/download/33133/20820. Acesso em: 6 jul. 2019.

CADASTRO NACIONAL DE ESTABELECIMENTOS DE SAÚDE. Consulta estabelecimento identificação. Cadastro Nacional de Estabelecimentos de Saúde, 2019. Disponível em: http://cnes.datasus.gov.br/pages/estabelecimentos/consulta.jsp. Acesso em: 22 abril 2019.

CAMELO-ORDAZ, C. et al. The influence of human resource management on knowledge sharing and innovation in Spain: the mediating role of affective commitment. The International Journal of Human Resource Management, v. 22, n. 7, p. 1442-1463, april 2011. Disponível em: https://www.tandfonline.com/doi/abs/10.1080/09585192.2011.561960. Acesso em: 6 jul. 2019.

CANDI, M. et al. Social strategy to gain knowledge for innovation. British Journal of Management, v. 29, n. 4, p. 731-749, january 2018. Disponível em: https://onlinelibrary.wiley.com/doi/10.1111/1467-8551.12280. Acesso em: 6 jul. 2019.

CAPURRO, R. Gestão do conhecimento cético. Perspectivas em Gestão \& Conhecimento, João Pessoa, v. $1, \quad$ n. 1 , p. 4-14, jan/jun 2011. Disponível em: 
http://www.periodicos.ufpb.br/index.php/pgc/article/view/10255/5622. Acesso em: 6 jul. 2019.

CARLSON, C. R.; WILMOT, W. W. Innovation: the five disciplines for creating what customers want. New York: Crown Business, 2006.

CARVALHO, A. P. et al. The role and contributions of sociological institutional theory to the socio-technical approach to innovation theory. Revista de Administração e Inovação, v. 14, n. 3, p. 250-259, 2017. Disponível em: https://www.sciencedirect.com/science/article/pii/S1809203917300621. Acesso em: 6 jul. 2019.

CARVALHO, H. Análise multivariada de dados qualitativos. 1. ed. Lisboa: Sílabo, 2008.

CERNE, M. et al. What goes around comes around: knowledge hiding, perceived motivational climate, and creativity. Academy of Management Journal, v. 57, n. 1, p. 172-192, february 2014. Disponível em: https://journals.aom.org/doi/10.5465/amj.2012.0122. Acesso em: 6 jul. 2019.

CHARNESS, G.; GRIECCO, D. Creativity and Incentives. Journal of the European Economic Association, v. 17, n. 2, p. 454-496, april 2019. Disponível em: https://academic.oup.com/jeea/advance-article-abstract/doi/10.1093/jeea/jvx055/4931135.

Acesso em: 6 jul. 2019.

$\mathrm{CHOO}, \mathrm{C}$. W. The knowing organization: how organizations use information to construct meaning, create knowledge, and make decisions. 2. ed. Oxford: Oxford University Press, 2006.

CHRISTOPHER, D.; TANWAR, A. Knowledge Management in outsourcing environment: people empowering people. The IUP Journal of Knowledge Management, v. X, n. 2, p. 61-86, 2012. Disponível em: https://papers.ssrn.com/sol3/papers.cfm?abstract id=2158513. Acesso em: 6 jul. 2019.

CIRELLA, S. Organizational variables for developing collective creativity in business: a case from an italian fashion design company. Creativity and Innovation Management, v. 25, n. 3, p. 331343, september 2016. Disponível em: https://onlinelibrary.wiley.com/doi/abs/10.1111/caim.12189. Acesso em: 6 jul. 2019.

CLAUß, T. The influence of the type of relationship on the generation of innovations in buyersupplier collaborations. Creativity and Innovation Management, v. 21, n. 4, p. 388-411, 2012. Disponível em: https://onlinelibrary.wiley.com/doi/abs/10.1111/i.1467-8691.2012.00651.x. Acesso em: 6 jul. 2019.

COLAUTO, R. D.; BEUREN, I. M. Proposta para avaliação da gestão do conhecimento em entidade filantrópica: o caso de uma organização hospitalar. Revista de Administração Contemporânea, Maringá, v. 7, n. 4, p. 163-185, out./dez. 2003. Disponível em: http://www.scielo.br/scielo.php?script=sci abstract\&pid=S141565552003000400009\&lng=en\&nrm=iso\&tlng=pt. Acesso em: 6 jul. 2019.

COOPER, A. L. et al. Knowledge management for logistics service providers: the role of learning culture. Industrial Management \& Data Systems, v. 116, n. 3, p. 584-602, 2016. Disponível em: https://www.emeraldinsight.com/doi/abs/10.1108/IMDS-06-2015-0262. Acesso em: 6 jul. 2019.

COOPER, D. R.; SCHINDLER, P. S. Métodos de pesquisa em Administração. 7. ed. Porto Alegre: Bookman, 2003. 
CORREA, F.; ZIVIANI, F.; MARTINS, H. C. A gestão do conhecimento holística: análise de aderência do modelo de Teixeira Filho (2000). Perspectivas em Gestão \& Conhecimento, João Pessoa, v. 8, n. número especial, p. 167-182, out. 2018. Disponível em: http://www.periodicos.ufpb.br/index.php/pgc/article/view/42081/21131. Acesso em: 6 jul. 2019.

CULPEPPER, M. K. KEYS to creativity and innovation: an adopt-a-measure examination. The International Center for Studies in Creativity, Buffalo State College, p. 1-19, 2010.

DAVILA, A.; DITILLO, A. Management control systems for creative teams: managing stylistic creativity in fashion companies. Journal of Management Accounting Research, v. 29, n. 3, p. 27-47, fall 2017. Disponível em: https://aaapubs.org/doi/10.2308/jmar-51806. Acesso em: 6 jul. 2019.

DAVIS, J. P.; EISENHARDT, K. M. Rotating leadership and collaborative innovation: recombination processes in symbiotic relationships. Administrative Science Quarterly, v. 56, n. 2. p. 159-201, june 2011.2 Disponível em: https://journals.sagepub.com/doi/abs/10.1177/0001839211428131. Acesso em: 6 jul. 2019.

DENFORD, J. S.; FERRISS, A. Absorption, combination and desorption: knowledge-oriented boundary spanning. Journal of Knowledge Management, v. 22, n. 7, p. 1425-1441, 2018. Disponível em: https://www.emeraldinsight.com/doi/abs/10.1108/JKM-08-2017-0325. Acesso em: 6 jul. 2019.

DENTI, L.; HEMLIN, S. Leadership and innovation in organizations: a systematic review of factors that mediate or moderate the relationship. International Journal of Innovation Management, v. 16, n. 3, p. 1-20, june 2012. Disponível em: https://www.worldscientific.com/doi/10.1142/S1363919612400075. Acesso em: 6 jul. 2019.

DIÉGUEZ-SOTO, J.; MANZANEQUE, M.; ROJO-RAMÍREZ, A. A. Technological innovation inputs, outputs, and performance: the moderating role of family involvement in management. Family Business Review, v. 29, n. 3, p. 327-346, may 2016. Disponível em: https://journals.sagepub.com/doi/10.1177/0894486516646917. Acesso em: 6 jul. 2019.

DONNELLY, R. Aligning knowledge sharing interventions with the promotion of firm success: the need for SHRM to balance tensions and challenges. Journal of Business Research, v. 94, p. 344-352, january 2019. Disponível em: https://www.sciencedirect.com/science/article/abs/pii/S0148296318300821. Acesso em: 6 jul. 2019.

DORAN, J.; O'LEARY, E. The innovation performance of Irish and foreign-owned firms: the roles of R\&D and networking. The World Economy, v. 39, n. 9, p. 1384-1398, january 2016. Disponível em: https://onlinelibrary.wiley.com/doi/full/10.1111/twec.12378. Acesso em: 6 jul. 2019.

DURAN, P. et al. Doing more with less: innovation input and output in family firms. The Academy of Management Journal, v. 59, n. 4, p. 1224-1264, august 2016. Disponível em: https://journals.aom.org/doi/10.5465/ami.2014.0424. Acesso em: 6 jul. 2019.

EISELE, P. Assessment of leadership for innovation and perceived organizational innovativeness: differences between self-reported individual and social creativity. International Journal of Organizational Leadership, v. 6, n. 4, p. 470-480, october 2017. Disponivel em: http://aimijournal.com/Pages/DownloadHandler.ashx?DownloadObject=Article\&ld=1ec0d408ef8f-4f1d-bc15-98adae87449c. Acesso em: 6 jul. 2019.

Perspectivas em Gestão \& Conhecimento, João Pessoa, v. 9, n. 2, p. 56-84, maio/ago. 2019. 
EVANS, M. M.; FRISSEN, I.; WENSLEY, A. K.P. Organisational information and knowledge sharing: uncovering mediating effects of perceived trustworthiness using the PROCESS approach. Journal of Information \& Knowledge Management, v. 17, n. 1, p. 1-29, march 2018. Disponível em: https://www.worldscientific.com/doi/abs/10.1142/S0219649218500016. Acesso em: 6 jul. 2019.

FÁVERO, L. P.L. et al. Análise de dados. Rio de Janeiro: Elsevier, 2009.

FERGUSON, M. Knowledge exchange between universities and the creative industries in the UK: a case study of current practice. Industry and Higher Education, v. 28, n. 3, p. 177-183, june 2014. Disponível em: https://journals.sagepub.com/doi/abs/10.5367/ihe.2014.0207. Acesso em: 6 jul. 2019.

FETRATI, M. A.; NIELSEN, A. P. The association between creativity and innovation: a literature review. ISPIM INNOVATION SYMPOSIUM, XXIX, 2018, Manchester. Proceedings... Manchester: The International Society for Professional Innovation Management, p. 1-14, 2018.

FIELD, A. Descobrindo a estatística usando o SPSS. 2. ed. Porto Alegre: Bookman, 2009.

FORSMAN, H.; TEMEL, S. From a non-innovator to a high-innovation performer: networking as a driver. Regional Studies, v. 50, n. 7, p. 1140-1153, october 2016. Disponível em: https://www.tandfonline.com/doi/abs/10.1080/00343404.2014.968120. Acesso em: 6 jul. 2019.

FORTWENGEL, J.; SCHUßLER, E.; SYDOW, J. Studying organizational creativity as process: fluidity or duality? Creativity and Innovation Management, v. 26, n. 1, p. 5-16, march 2017. Disponível em: https://onlinelibrary.wiley.com/doi/full/10.1111/caim.12187. Acesso em: 6 jul. 2019.

FRANCO, C.; OLIVEIRA, R. H. Inputs and outputs of innovation: analysis of the BRICS Theme 6 innovation technology and competitiveness. Revista de Administração e Inovação, São Paulo, v. 14, n. 1, p. 79-89, março 2017. Disponível em: https://www.sciencedirect.com/science/article/pii/S1809203916311275. Acesso em: 6 jul. 2019.

GEHL, R. W. Sharing, knowledge management and big data: a partial genealogy of the data scientist. European Journal of Cultural Studies, v. 18, n. 4-5, p. 413-428, june 2015. Disponível em: https://journals.sagepub.com/doi/10.1177/1367549415577385. Acesso em: 6 jul. 2019.

GILSON, L. L. et al. Unpacking the cross-level effects of tenure diversity, explicit knowledge, and knowledge sharing on individual creativity. Journal of Occupational and Organizational Psychology, v. 86, n. 2, p. 203-222, june 2013. Disponível em: https://onlinelibrary.wiley.com/doi/abs/10.1111/joop.12011. Acesso em: 6 jul. 2019.

GLAVEANU, V. P.; LUBART, T. Decentring the creative self: how others make creativity possible in creative professional fields. Creativity and Innovation Management, v. 23, n. 1, p. 29-43, march 2014. Disponível em: https://onlinelibrary.wiley.com/doi/abs/10.1111/caim.12049. Acesso em: 6 jul. 2019.

GOLD, A. H.; MALHOTRA, A.; SEGARS, A. H. Knowledge management: an organizational capabilities perspective. Journal of Management Information Systems, v. 18, n. 1, p. 185-241, $2001 . \quad$ Disponível em: https://www.tandfonline.com/doi/abs/10.1080/07421222.2001.11045669. Acesso em: 6 jul. 2019.

GOLLER, I.; BESSANT, J. Creativity for innovation management. Abingdon: Routledge, 2017. 
GOMES, J. F.S.; RODRIGUES, A. F.; VELOSO, A. Regresso às origens: a importância do indivíduo na criatividade nas organizações. Revista de Administração Contemporânea, Rio de Janeiro, v. 20, n. 5, p. 568-589, set./out. 2016. Disponível em: http://www.scielo.br/pdf/rac/v20n5/14156555-rac-20-05-00568.pdf. Acesso em: 6 jul. 2019.

GONÇALO, C. R.; BORGES, M. L. Organizações de saúde intensivas em conhecimento: um estudo no contexto de serviços de alta complexidade. Saúde e Sociedade, São Paulo, v. 19, n. 2, p. 449-461, junho $2010 . \quad$ Disponível em: http://www.scielo.br/scielo.php?script=sci abstract\&pid=S010412902010000200020\&tlng=pt. Acesso em: 6 jul. 2019.

GONG, Y. et al. A multilevel model of team goal orientation, information exchange, and creativity. Academy of Management Journal, v. 56, n. 3, p. 827-851, 2013. Disponível em: https://journals.aom.org/doi/10.5465/amj.2011.0177. Acesso em: 6 jul. 2019.

GONZALEZ, R. V.D.; MARTINS, M. F. Um estudo teórico das características organizacionais que influenciam a gestão do conhecimento nas organizações. Perspectivas em Gestão \& Conhecimento, João Pessoa, v. 5, n. 2, p. 14-34, jul./dez. 2015. Disponível em: http://www.periodicos.ufpb.br/index.php/pgc/article/view/21916/14382. Acesso em: 6 jul. 2019.

GRABNER, I. Incentive system design in creativity-dependent firms. The Accounting Review, v. 89, n. 5, p. 1729-1750, september 2014. Disponível em: https://www.aaapubs.org/doi/10.2308/accr-50756. Acesso em: 6 jul. 2019.

GRIESAR, K.; BESSANT, J.; BERNSCHNEIDER-REIF, S. The recipe for corporate longevity: from the perspective of "Managing innovation". Angewandte Chemie International Edition, v. 57, n. 16, p. 4130-4142, april 2018.2 Disponível em: https://onlinelibrary.wiley.com/doi/full/10.1002/anie.201712514. Acesso em: 6 jul. 2019.

GUILFORD, J. P. Creativity. American Psychologist, v. 5, n. 9, p. 444-454, 1950. Disponível em: https://psycnet.apa.org/doi/10.1037/h0063487. Acesso em: 6 jul. 2019.

HAHN, K. Innovation in times of financialization: Do future-oriented innovation strategies suffer? Examples from German industry. Research Policy, v. 48, n. 4, p. 923-935, may 2019. Disponível em: https://www.sciencedirect.com/science/article/pii/S0048733318302488. Acesso em: 6 jul. 2019.

HAIR JR, J. F. et al. Análise multivariada de dados. 5. ed. Porto Alegre: Bookman, 2005.

HANLEY, S. Measure what matters: a practical approach to knowledge management metrics. Business Information Review, v. 13, n. 3, p. 154-159, october 2014. Disponível em: https://journals.sagepub.com/doi/abs/10.1177/0266382114551120. Acesso em: 6 jul. 2019.

HERNANDEZ, J. M.C.; CALDAS, M. P. Resistência à mudança: uma revisão crítica. Revista de Administração de Empresas, São Paulo, v. 41, n. 2, p. 31-45, abril/junho 2001. Disponível em: http://www.scielo.br/pdf/rae/v41n2/v41n2a04. Acesso em: 6 jul. 2019.

HIRST, G. et al. Exploitation and exploration climates' influence on performance and creativity: diminishing returns as function of self-efficacy. Journal of Management, v. 44, n. 3, p. 870-891, march 2018. Disponível em: https://doi.org/10.1177/0149206315596814. Acesso em: 6 jul. 2019.

HORA, H. R.M.; MONTEIRO, G. T.R.; ARICA, J. Confiabilidade em questionários para qualidade: um estudo com o coeficiente Alfa de Cronbach. Produto \& Produção, v. 11, n. 2, p. 85-103, 
junho 2010. Disponível em: https://seer.ufrgs.br/ProdutoProducao/article/view/9321. Acesso em: 6 jul. 2019.

JOHANSON, B.; LOOF, H. Innovation strategies combining internal and external knowledge. Centre of Excellence for Science and Innovation Studies. Stockholm: CESIS, p. 1-39. 2016. (436).

JONES, R. J.; BARNIR, A. Properties of opportunity creation and discovery: comparing variation in contexts of innovativeness. Technovation, v. 79, p. 1-10, january 2019. Disponível em: https://www.sciencedirect.com/science/article/pii/S0166497218301214. Acesso em: 6 jul. 2019.

KINDER, T.; STENVALL, J.; MEMON, A. Play at work, learning and innovation. Public Management Review, v. 21, n. 3, p. 376-399, 2019. Disponível em: https://www.tandfonline.com/doi/abs/10.1080/14719037.2018.1487578. Acesso em: 6 jul. 2019.

KREMER, H.; VILLAMOR, I.; AGUINIS, H. Innovation leadership: best-practice recommendations for promoting employee creativity, voice, and knowledge sharing. Business Horizons, v. 62, n. 1 p. 65-74, january-february 2019. Disponível em: https://www.sciencedirect.com/science/article/pii/S0007681318301459. Acesso em: 6 jul. 2019.

LAING, G. K. Seismic measurement of management accounting innovations: using the scale of innovation intensity. Management Accounting Frontiers, p. 3-14, october 2018. Disponível em: $\quad$ https://www.cmawebline.org/ontarget/seismic-measurement-of-managementaccounting-innovations-using-the-scale-of-innovation-intensity/. Acesso em: 6 jul. 2019.

LINTON, G. Innovativeness, risk-taking, and proactiveness in startups: a case study and conceptual development. Journal of Global Entrepreneurship Research, v. 9, n. 20, p. 1-21, january 2019. Disponível em: https://journal-iger.springeropen.com/articles/10.1186/s40497019-0147-5. Acesso em: 6 jul. 2019.

LOMBARDO, R.; BEH, E. J. Simple and multiple correspondence analysis for ordinal-scale variables using orthogonal polynomials. Journal of Applied Statistics, v. 37, n. 12, p. 21012116, $2010 . \quad$ Disponível em: https://www.tandfonline.com/doi/abs/10.1080/02664760903247692. Acesso em: 6 jul. 2019.

LONGONI, A.; CAGLIANO, R. Sustainable innovativeness and the triple bottom line: the role of organizational time perspective. Journal of Business Ethics, v. 151, n. 4, p. 1097-1120, september 2018. Disponível em: https://link.springer.com/article/10.1007/s10551-016-3239y. Acesso em: 6 jul. 2019.

LOON, M. Knowledge management practice system: theorising from an international metastandard. Journal of Business Research, v. 94, p. 432-441, january 2019. Disponível em: https://www.sciencedirect.com/science/article/abs/pii/S014829631730468X. Acesso em: 6 jul. 2019.

LOWE, N.; FELDMAN, M. P. Breaking the waves: innovating at the intersections of economic development. Economic Development Quarterly, v. 32, n. 3, p. 183-194, 2018. Disponível em: https://journals.sagepub.com/doi/10.1177/0891242418783848. Acesso em: 6 jul. 2019.

LUPTON, N.; BEAMISH, P. Organizational structure and knowledge-practice diffusion in the MNC. Journal of Knowledge Management, v. 18, n. 4, p. 710-727, 2014. Disponível em: https://www.emeraldinsight.com/doi/10.1108/JKM-11-2013-0448. Acesso em: 6 jul. 2019. 
MACEDO, V. et al. Tipologia do trabalhador do conhecimento: papéis e processos. Perspectivas em Gestão \& Conhecimento, João Pessoa, v. 7, n. número especial, p. 94-108, mar. 2017.2 Disponível em: http://www.periodicos.ufpb.br/index.php/pgc/article/view/33081/17294. Acesso em: 6 jul. 2019.

MACHADO, H. P.V. Configuração de estudos sobre gestão do conhecimento em pequenas empresas no Brasil. Perspectivas em Gestão \& Conhecimento, João Pessoa, v. 8, n. 3, p. 209227, set./dez. 2018. Disponível em: http://www.periodicos.ufpb.br/index.php/pgc/article/view/33758/21774. Acesso em: 6 jul. 2019.

MALIK, A. M. Desenvolvimento de recursos humanos, gerência de qualidade e cultura das organizações de saúde. Revista de Administração de Empresas, São Paulo, v. 32, n. 4, p. 32-41, set./out. 1992. Disponível em: http://www.scielo.br/scielo.php?script=sci arttext\&pid=S003475901992000400004. Acesso em: 6 jul. 2019.

MAROCO, J.; GARCIA-MARQUES, T. Qual a fiabilidade do alfa de Cronbach? Questões antigas e soluções modernas? Laboratório de Psicologia, v. 4, n. 1, p. 65-90, 2006. Disponível em: http://publicacoes.ispa.pt/index.php/lp/article/viewFile/763/706. Acesso em: 6 jul. 2019.

MARQUES, J. M.R. et al. The relationship between organizational commitment, knowledge transfer and knowledge management maturity. Journal of Knowledge Management, v. 23, n. 1, p. 67-89, 2019. Disponível em: https://www.emerald.com/insight/content/doi/10.1108/JKM-03-2018-0199/full/html. Acesso em: 6 jul. 2019.

MCDOWELL, W. C. et al. Building small firm performance through intellectual capital development: exploring innovation as the "black box". Journal of Business Research, v. 88, p. 321-327, february 2018. Disponivel em: https://www.sciencedirect.com/science/article/pii/S0148296318300249. Acesso em: 6 jul. 2019.

MCIVER, D.; FITZSIMMONS, S.; FLANAGAN, D. Instructional design as Knowledge Management: a knowledge-in-practice approach to choosing instructional methods. Journal of Management Education, v. 40, n. 1, p. 47-75, 2016. Disponível em: https://journals.sagepub.com/doi/full/10.1177/1052562915587583. Acesso em: 6 jul. 2019.

MELO, C.; TANAKA, O. As organizações sociais no setor saúde: inovando as formas de gestão? Organizações \& Sociedade, Salvador, v. 8, n. 22, p. 1-12, set./dez. 2001. Disponível em: http://www.scielo.br/scielo.php?script=sci arttext\&pid=S1984-92302001000300007. Acesso em: 6 jul. 2019.

MOULANG, C. Performance measurement system use in generating psychological empowerment and individual creativity. Accounting and Finance, v. 55, n. 2, p. 519-544, june 2015. Disponível em: https://onlinelibrary.wiley.com/doi/abs/10.1111/acfi.12059. Acesso em: 6 jul. 2019.

MUZZIO, H. Indivíduo, liderança e cultura: evidências de uma gestão da criatividade. Revista de Administração Contemporânea, São Paulo, v. 21, n. 1, p. 107-124, jan./fev. 2017. Disponível em: $\quad$ http://www.scielo.br/scielo.php?script=sci abstract\&pid=S141565552017000100107\&lng=en\&nrm=iso\&tlng=pt. Acesso em: 6 jul. 2019.

MUZZIO, H.; PAIVA JÚNIOR, F. G. Organizational creativity management: discussion elements. Revista de Administração Contemporânea, Rio de Janeiro, v. 22, n. 6, p. 922-939, 
novembro/dezembro 2018. Disponível em: http://www.scielo.br/pdf/rac/v22n6/1982-7849rac-22-06-0922.pdf. Acesso em: 6 jul. 2019.

NANDITA, S. Improving organization performance through Knowledge Management practices. Advances in Management, v. 6, n. 2, p. 56-60, february 2013. Disponível em: https://ideas.repec.org/a/mgn/journl/v6y2013i2a9.html. Acesso em: 6 jul. 2019.

NASIEROWSKI, W.; ARCELUS, F. J. What is Innovativeness: literature review. Foundations of Management, v. 4, n. 1, p. 63-74, january 2012. Disponível em: https://content.sciendo.com/view/journals/fman/4/1/article-p63.xml. Acesso em: 6 jul. 2019.

NEVES, M. L.C. et al. Gestão do conhecimento no Brasil: a abordagem dos textos jornalísticos. Perspectivas em Gestão \& Conhecimento, João Pessoa, v. 8, n. 3, p. 228-242, set./dez. 2018. Disponível em: http://www.periodicos.ufpb.br/index.php/pgc/article/view/33789/21775. Acesso em: 6 jul. 2019.

NONAKA, I.; HIROSE, A.; TAKEDA, Y. 'Meso'-foundations of dynamic capabilities: team-level synthesis and distributed leadership as the source of dynamic creativity. Global Strategy Journal, v. 6 , n. 3, p. 168-182, august 2016. Disponível em: https://onlinelibrary.wiley.com/doi/full/10.1002/gsj.1125. Acesso em: 6 jul. 2019.

NONAKA, I.; TAKEUCHI, $\mathrm{H}$. The knowledge-creating company: how japanese companies create the dynamics of innovation. New York: Oxford University Press, 1995.

NOWACKI, R.; BACHNIK, K. Innovations within knowledge management. Journal of Business Research, v. 69, n. 5, p. 1577-1581, may 2016. Disponível em: https://www.sciencedirect.com/science/article/pii/S0148296315004439. Acesso em: 6 jul. 2019.

OLIVA, F. L. et al. Innovation in the main Brazilian business sectors: characteristics, types and comparison of innovation. Journal of Knowledge Management, v. 23, n. 1, p. 135-175, 2019. Disponível em: https://www.emerald.com/insight/content/doi/10.1108/JKM-03-20180159/full/html. Acesso em: 6 jul. 2019.

OLIVEIRA, P. H.; TERENCE, A. C.F. Innovation practices in small technology-based companies during incubation and post-incubation periods. Innovation \& Management Review, v. 15, n. 2, p. 174-188, 2018. Disponível em: https://www.revistas.usp.br/rai/article/view/151130. Acesso em: 6 jul. 2019.

ORGANISATION FOR ECONOMIC CO-OPERATION AND DEVELOPMENT. Oslo manual 2018: guidelines for collecting and interpreting innovation data. 4. ed. Paris: OECD Publishing, 2018.

PADILHA, C. K.; GOMES, G. Innovation culture and performance in innovation of products and processes:a study in companies of textile industry. Revista de Administração e Inovação, v. 13, n. 4, p. 285-294, october 2016.2 Disponível em: https://www.sciencedirect.com/science/article/pii/S1809203916310749. Acesso em: 6 jul. 2019.

PAIM, J. et al. O sistema de saúde brasileiro: história, avanços e desafios. The Lancet, London: Elsevier, 92 maio 2011.2 Disponível em: http://www6.ensp.fiocruz.br/repositorio/resource/352546. Acesso em: 6 jul. 2019.

PARK, H. D.; HOWARD, M. D.; GOMULYA, D. M. The impact of knowledge worker mobility through an acquisition on breakthrough knowledge. Journal of Management Studies, v. 55, n. 1 p. 86-107, january 2018.20 Disponível em: https://onlinelibrary.wiley.com/doi/10.1111/joms.12320. Acesso em: 6 jul. 2019. 
PAULA, F. L. et al. Perfil de idosos com internação por quedas nos hospitais públicos de Niterói (RJ). Revista Brasileira de Epidemiologia, São Paulo, v. 13, n. 4, p. 587-595, 2010. Disponível em: http://www.scielo.br/scielo.php?pid=S1415790X2010000400004\&script=sci abstract\&tlng=pt. Acesso em: 6 jul. 2019.

PEREIRA, F. C.M.; SILVA, E. F. Criação do conhecimento organizacional baseada nos capacitadores de von Krogh, Nonaka e Ichijo: estudo de caso. Perspectivas em Gestão \& Conhecimento, João Pessoa, v. 8, n. 1, p. 20-43, jan./abr. 2018. Disponível em: http://www.periodicos.ufpb.br/index.php/pgc/article/view/32751/19960. Acesso em: 6 jul. 2019.

PITASSI, C.; GONÇALVES, A. A.; MORENO JÚNIOR, V. A. Fatores que influenciam a adoção de ferramentas de TIC nos experimentos de bioinformática de organizações biofarmacêuticas: um estudo de caso no Instituto Nacional do Câncer. Ciência \& Saúde Coletiva, Rio de Janeiro, v. 19, n. 1, p. 257-268, janeiro 2014. Disponível em: http://www.scielo.br/scielo.php?pid=S141381232014000100257\&script=sci abstract\&tlng=pt. Acesso em: 6 jul. 2019.

PRADO, J. C.A.; FISCHER, A. L. Condiciones de la gestión del conocimiento, capacidad de innovación y resultados empresariales: un modelo explicativo. Pensamiento \& Gestión, Barranquilla, v. 37, p. 25-63, julio/diciembre 2013. Disponível em: http://rcientificas.uninorte.edu.co/index.php/pensamiento/article/view/6104/3514. Acesso em: 6 jul. 2019.

QUANDT, C. O.; FERRARESI, A.; BEZERRA, C. A. Organizational innovativeness and innovative performance: a multidimensional model. XVII CONGRESO LATINO-IBEROAMERICANO DE GESTIÓN TECNOLÓGICA, 17, 2017, Ciudad de México. Anales... Ciudad de México: ALTEC, 2017. p. 1-15.

RAMOS, M. A.W.; FIGUEIREDO, P. S.; PEREIRA-GUIZZO, C. Antecedents of innovation in industry: the impact of work environment factors on creative performance. Innovation \& Management Review, v. 15, n. 3, p. 269-285, 2018. Disponível em: https://www.emeraldinsight.com/doi/abs/10.1108/INMR-05-2018-0032. Acesso em: 6 jul. 2019.

RANK, O. N.; STRENGE, M. Entrepreneurial orientation as a driver of brokerage in external networks: exploring the effects of risk taking, proactivity, and innovativeness. Strategic Entrepreneurship Journal, v. 12, n. 4, p. 482-503, december 2018. Disponível em: https://onlinelibrary.wiley.com/doi/abs/10.1002/sej.1290. Acesso em: 6 jul. 2019.

REIS, C. et al. Saúde. In: PUGA, F. P.; CASTRO, L. B. Visão 2035: Brasil, país desenvolvido: Agendas setoriais para alcance da meta. Rio de Janeiro: Banco Nacional de Desenvolvimento Econômico e Social, p. 289-312, 2018.

RIBEIRO, G.; CHEROBIM, A. P.M.S. Environment and innovation: discrepancy between theory and research practice. Revista de Administração e Inovação, v. 14, n. 1, p. 30-40, 2017. Disponível em: http://www.revistas.usp.br/rai/article/view/114449. Acesso em: 6 jul. 2019.

RIBIÈRE, V.; WALTER, C. 10 years of KM theory and practices. Knowledge Management Research \& Practice, v. 11, n. 1, p. 4-9, february 2013. Disponível em: https://www.tandfonline.com/doi/abs/10.1057/kmrp.2012.64. Acesso em: 6 jul. 2019.

RICE, R. E.; HEINZ, M.; VAN ZOONEN, W. A public goods model of outcomes from online knowledge sharing mediated by mental model processing. Journal of Knowledge Management, v. 23, n. 1, p. 1-22, 2019. Disponível em: https://www.emeraldinsight.com/doi/abs/10.1108/JKM-06-2018-0360. Acesso em: 6 jul. 2019. 
ROACH, D. et al. Enhancing innovativeness: the role of dynamic marketing capabilities. Canadian Journal of Administrative Sciences, v. 35, n. 4, p. 563-576, december 2018. Disponível em: https://onlinelibrary.wiley.com/doi/10.1002/cjas.1473. Acesso em: 6 jul. 2019.

RODRÍGUEZ-SÁNCHEZ, A. M. et al. What makes creative teams tick? Cohesion, engagement, and performance across creativity tasks: a three-wave study. Group \& Organization Management, v. 42, n. 2, p. 521-547, august 2017. Disponível em: https://journals.sagepub.com/doi/10.1177/1059601116636476. Acesso em: 6 jul. 2019.

ROLDAN, L. B.; HANSEN, P. B.; GARCIA-PEREZ-DE-LEMA, D. The relationship between favorable conditions for innovation in technology parks, the innovation produced, and companies' performance: a framework for an analysis model. Innovation \& Management Review, v. 15, n. 3, p. 286-302, 2018. Disponível em: https://www.emeraldinsight.com/doi/full/10.1108/INMR05-2018-0027. Acesso em: 6 jul. 2019.

ROSELLO, J.; TRAN, V. Assessing the climate for creativity: the example of a french high-tech organization. 12TH EUROPEAN CONFERENCE ON CREATIVITY AND INNOVATION, 12, 2011, Faro. Proceedings... Faro: EACl, p. 581-596, 2011.

RUIZ, P. P. Knowledge management oxymoron's: introducing human factors to bring theory to practice. University of Bath. [S.I.]: Open Innovative, p. 1-10. 2010. (Paper).

SANTOS, B. R.P.; SANTOS, C. A.; DAMIAN, I. P.M. A gestão do conhecimento e sua relação com a competência em informação: proposta de transversalidade como subsídios inovadores para as organizações contemporâneas. Perspectiva em Gestão \& Conhecimento, João Pessoa, v. 8, n. especial, p. 183-199, out. 2018.2 Disponível em: http://www.periodicos.ufpb.br/index.php/pgc/article/view/42088/21132. Acesso em: 6 jul. 2019.

SARAYREH, B.; MARDAWI, A.; DMOUR, R. Comparative study: the Nonaka model of Knowledge Management. International Journal of Engineering and Advanced Technology, v. 1, n. 6, p. 45-48, august 2012. Disponível em: http://orca.cf.ac.uk/119480/. Acesso em: 6 jul. 2019.

SCATOLIN, H. G. A gestão do conhecimento nas organizações: o legado de Nonaka e Takeuchi. Perspectivas em Gestão \& Conhecimento, João Pessoa, v. 5, n. 2, p. 4-13, jul./dez. 2015. Disponível em: http://www.periodicos.ufpb.br/index.php/pgc/article/view/21772/14381. Acesso em: 6 jul. 2019.

SCHIAVI, G. S.; BEHR, A. Emerging technologies and new business models: a review on disruptive business models. Innovation \& Management Review, v. 15, n. 4, p. 338-355, 2018. Disponível em: https://www.emerald.com/insight/content/doi/10.1108/INMR-03-20180013/full/html. Acesso em: 6 jul. 2019.

SCHOEMAKER, P. J.H.; HEATON, S.; TEECE, D. Innovation, dynamic capabilities, and leadership. California Management Review, v. 61, n. 1, p. 15-42, august 2018. Disponível em: https://journals.sagepub.com/doi/abs/10.1177/0008125618790246. Acesso em: 6 jul. 2019.

SCHUMPETER, J. A. The theory of economic development. Cambridge: Transaction Books, 1934.

SMITH, G. Bullying versus creativity: mutually exclusive workplace behaviors. Advances in Social Sciences Research Journal, v. 4, n. 14, p. 220-224, july 2017. Disponível em: https://journals.scholarpublishing.org/index.php/ASSRJ/article/view/3522. Acesso em: 6 jul. 2019. 
SOETE, L. Science, technology and innovation studies at a crossroad: SPRU as case study. Research Policy, v. 48, n. 4, p. 849-857, may 2019. Disponível em: https://www.sciencedirect.com/science/article/pii/S0048733318302695. Acesso em: 6 jul. 2019.

SOOD, A.; TELLIS, G. J. Do innovations really pay off? Total stock market returns to innovation. Marketing Science, v. 28, n. 3, p. 442-456, may-june 2009. Disponível em: https://www.jstor.org/stable/23884198. Acesso em: 6 jul. 2019.

STERNBERG, R. J. A triangular theory of creativity. Psychology of Aesthetics, Creativity, and the Arts, v. 12 , n. 1 , p. 50-67, february 2018. Disponível em: https://psycnet.apa.org/record/2016-60691-001. Acesso em: 6 jul. 2019.

STROLL, D.; KORHONEN, J. J. Empirical measurement of innovation diffusion: a new approach. XXIX ISPIM INNOVATION CONFERENCE, 24, 2018, Stockholm. Proceedings... Manchester: The International Society for Professional Innovation Management. p. 1-14, 2018.

SWAN, J.; SCARBROUGH, H.; ZIEBRO, M. Liminal roles as a source of creative agency in management: the case of knowledge-sharing communities. Human Relations, v. 69, n. 3, p. 781-811, november 2015.2 Disponível em: https://journals.sagepub.com/doi/10.1177/0018726715599585. Acesso em: 6 jul. 2019.

TEECE, D. J. Business models and dynamic capabilities. Long Range Planning, v. 51, n. 1, p. 4049, february 2018. Disponível em: https://www.sciencedirect.com/science/article/pii/S0024630117302868. Acesso em: 6 jul. 2019.

TEECE, D. J. Profiting from innovation in the digital economy: enabling technologies, standards, and licensing models in the wireless world. Research Policy, v. 47, n. 8, p. 1367-1387, october 2018. Disponível em: https://www.sciencedirect.com/science/article/pii/S0048733318300763. Acesso em: 6 jul. 2019.

TERSTRIEP, J.; LUTHJE, C. Innovation, knowledge and relations - on the role of clusters for firms' innovativeness. European Planning Studies, v. 26, n. 11, p. 2167-2199, october 2018. Disponivel em: https://www.tandfonline.com/doi/full/10.1080/09654313.2018.1530152. Acesso em: 6 jul. 2019.

THALMANN, S.; SARIGIANNI, C. Knowledge protection the unexplored knowledge management strategy. In: WIMMER, P. Wissen im prozess: beiträge zu den kremser wissensmanagementtagen 2015. Krems: Donau-Universitat Krems, p. 141-151, 2016.

TIDD, J.; BESSANT, J. Innovation management challenges: from fads to fundamentals. International Journal of Innovation Management, v. 22, n. 5, p. 1-13, june 2018. Disponível em: https://www.worldscientific.com/doi/abs/10.1142/S1363919618400078. Acesso em: 6 jul. 2019.

VASCONCELOS, C. R. Inovação em empresas prestadoras de serviços de saúde: uma contribuição através da metodologia de Kano. Revista de Gestão em Sistemas de Saúde, São Paulo, v. 3, n. 1, p. 57-69, jan./jun. 2014. Disponível em: http://www.revistargss.org.br/ojs/index.php/rgss/article/view/64. Acesso em: 6 jul. 2019.

VASCONCELOS, R. B.B.; OLIVEIRA, M. R.G. Determinantes da inovação em micro e pequenas empresas: uma abordagem gerencial. Revista de Administração de Empresas, São Paulo, v. 58, n. 4, p. 349-364, jul-ago 2018. Disponível em: https://rae.fgv.br/rae/vol58-num42018/determinantes-inovacao-em-micro-pequenas-empresas-abordagem-gerencial-versao. Acesso em: 6 jul. 2019. 
VASCONCELOS, R.; OLIVEIRA, M. Does innovation make a difference? An analysis of the performance of micro and small enterprises in the food service industry. Innovation \& Management Review, v. 15, n. 2, p. 137-154, 2018. Disponível em: https://www.emerald.com/insight/content/doi/10.1108/INMR-04-2018-011/full/html. Acesso em: 6 jul. 2019.

VINCENT, L. C.; KOUCHAKI, M. Creative, rare, entitled, and dishonest: how commonality of creativity in one's group decreases an individual's entitlement and dishonesty. Academy of Management Journal, v. 59, n. 4, p. 1451-1473, august 2015. Disponível em: https://journals.aom.org/doi/10.5465/amj.2014.1109. Acesso em: 6 jul. 2019.

VON KROGH, G.; ICHIJO, K.; NONAKA, I. Enabling knowledge creation. Oxford: Oxford University Press, 2000.

VON KROGH, G.; ROOS, J. Organizational epistemology. Hampshire: MacMillan Press, 1995.

VOS, M. A. et al. Balancing modularity and solution space freedom: effects on organisational learning and sustainable innovation. International Journal of Production Research, v. 56, n. 20, p. 6658-6677, april 2018. Disponível em: https://www.tandfonline.com/doi/full/10.1080/00207543.2018.1458165. Acesso em: 6 jul. 2019.

WALSH, J. N.; O'BRIEN, J. Knowledge asymmetries and service management: three case studies. Journal of Information \& Knowledge Management, v. 17, n. 3, p. 1-26, 2018. Disponível em: https://www.worldscientific.com/doi/abs/10.1142/S0219649218500247. Acesso em: 6 jul. 2019.

WIIG, K. M. Knowledge Management foundations: how people and organizations create, represent, and use knowledge. Arlington: Schema Press, v. 1, 1995.

WILSON, M. C. Creativity, probability and uncertainty. Journal of Economic Methodology, v. 16, n. 1, p. 45-56, march 2009. Disponível em: https://www.tandfonline.com/doi/abs/10.1080/13501780802684252. Acesso em: 6 jul. 2019. 